\title{
The B-cell antigen receptor signals through a preformed transducer module of SLP65 and CIN85
}

EMBO open

\section{Thomas Oellerich ${ }^{1}$, Vanessa Bremes ${ }^{1}$, Konstantin Neumann ${ }^{1}$, Hanibal Bohnenberger ${ }^{1}$, Kai Dittmann ${ }^{1}$, He-Hsuan Hsiao $^{2}$, Michael Engelke ${ }^{1}$, Tim Schnyder ${ }^{3}$, Facundo D Batista ${ }^{3}$, Henning Urlaub ${ }^{2,4, *}$ and Jürgen Wienands ${ }^{1, *}$}

${ }^{1}$ Institute of Cellular and Molecular Immunology, Georg-August-University Göttingen, Göttingen, Germany, ${ }^{2}$ Bioanalytical Mass Spectrometry Group, Max Planck Institute for Biophysical Chemistry, Göttingen, Germany, ${ }^{3}$ Lymphocyte Interaction Laboratory, Cancer Research UK, London Research Institute, London, UK and ${ }^{4}$ Bioanalytics, Department of Clinical Chemistry, University Medical Center, Georg-August-University Göttingen, Göttingen, Germany

Spleen tyrosine kinase Syk and its substrate SLP65 (also called BLNK) are proximal signal transducer elements of the B-cell antigen receptor (BCR). Yet, our understanding of signal initiation and processing is limited owing to the incomplete list of SLP65 interaction partners and our ignorance of their association kinetics. We have now determined and quantified the in vivo interactomes of SLP65 in resting and stimulated B cells by mass spectrometry. SLP65 orchestrated a complex signal network of about 30 proteins that was predominantly based on dynamic interactions. However, a stimulation-independent and constant association of SLP65 with the Cbl-interacting protein of $85 \mathrm{kDa}$ (CIN85) was requisite for SLP65 phosphorylation and its inducible plasma membrane translocation. In the absence of a steady SLP65/CIN85 complex, BCR-induced $\mathrm{Ca}^{2+}$ and NF-кB responses were abrogated. Finally, live cell imaging and co-immunoprecipitation experiments further confirmed that both SLP65 and CIN85 are key components of the BCR-associated primary transducer module required for the onset and progression phases of BCR signal transduction.

The EMBO Journal (2011) 30, 3620-3634. doi:10.1038/

emboj.2011.251; Published online 5 August 2011

Subject Categories: signal transduction; immunology

Keywords: adaptor proteins; B-cell receptor; proteome analysis; tyrosine kinase

\footnotetext{
*Corresponding authors. J Wienands, Institute of Cellular and Molecular Immunology, Georg-August-University Göttingen, Humboldtallee 34, Göttingen 37073, Germany. Tel.: + 4955139 5821; Fax: + 4955139 5843; E-mail: jwienan@uni-goettingen.de or H Urlaub, Bioanalytical Mass Spectrometry Group, Max Planck Institute for Biophysical Chemistry, Am Fassberg 11, 37077 Göttingen, Germany. Tel.: + 49551201 1060; Fax: + 49551201 1197;

E-mail: henning.urlaub@mpibpc.mpg.de
}

Received: 15 February 2011; accepted: 5 July 2011; published online: 5 August 2011

\section{Introduction}

Two biochemical principles characterize initiation and processing of antigen-induced signalling in lymphocytes. First, antigen receptor-proximal effector proteins assemble into multimeric complexes in a rapid and transient manner. Second, the formation of these early signalosomes is accompanied by subcellular relocation of one or more of the molecules involved, most prominently from the cytosol into signalling-competent membrane microdomains. The activated B-cell antigen receptor (BCR) recruits the tandemly arranged Src homology (SH) 2 domains of spleen tyrosine kinase Syk (Zioncheck et al, 1988; Hutchcroft et al, 1991, 1992) to a phosphorylated immunoreceptor tyrosine-based activation motif (ITAM) in Ig $\alpha$ (CD79a) and $\operatorname{Ig} \beta$ (CD79b) (for review, see Engels et al, 2008 and Geahlen, 2009). Syk and its phospho-ITAM-mediated activation provide a common trigger for many B-cell signalling cascades including $\mathrm{Ca}^{2+}$ mobilization (Engelke et al, 2007; Scharenberg et al, 2007), induction of MAP kinase pathways (Hashimoto et al, 1998; Jiang et al, 1998) and nuclear translocation of transcription-

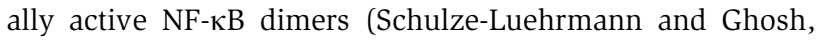
2006).

The proximal and dominant Syk substrate in BCR-stimulated cells is the SH2 domain-containing leukocyte adaptor protein of $65 \mathrm{kDa}$ (SLP65; Wienands et al, 1998) alternatively named BLNK (Fu et al, 1998) or BASH (Goitsuka et al, 1998). Nine tyrosine residues become rapidly phosphorylated upon BCR activation (Oellerich et al, 2009). Together with the complex involvement of 29 serine and 6 threonine residues intricate phosphorylation patterns are generated which enable SLP65 to act upstream for triggering the signal as well as downstream during selective processing of the BCR signal (Oellerich et al, 2009). Hence, SLP65 is a genuine signal integrator which is as mandatory as Syk for normal B lymphopoiesis and humoral immunity (Jumaa et al, 1999; Minegishi et al, 1999; Pappu et al, 1999; Hayashi et al, 2000; $\mathrm{Xu}$ et al, 2000).

Fulfilling the signal integration function requires differential networking of SLP65 with numerous interaction partners. This has been worked out to a great detail for the SLP65mediated nucleation of the $\mathrm{Ca}^{2+}$ initiation complex. Three distinct phosphotyrosine residues in SLP65 serve as docking sites for the SH2 domains of phospholipase C- $\gamma 2$ (PLC- $\gamma 2$ ) and Bruton's tyrosine kinase (Btk) (Hashimoto et al, 1999; Ishiai et al, 1999; Su et al, 1999; Chiu et al, 2002). Within this trimolecular arrangement Btk phosphorylates and thereby activates PLC- $\gamma 2$. It remained unclear how the $\mathrm{Ca}^{2+}$ initiation complex anchors inducibly to the plasma membrane to provide PLC- $\gamma 2$ with access to its substrate phosphatidylinositol-4,5 bisphosphate, which upon hydrolysis yields the second messengers inositol-trisphosphate and diacylglycerol. Mutational analysis revealed that membrane recruitment of SLP65 requires both the $\mathrm{N}$-terminal basic region and the C-terminal SH2 domain (Kohler et al, 2005; Abudula et al, 
2007). A ligand for the basic effector region has not yet been identified. Binding of the $\mathrm{SH} 2$ domain to a non-ITAM phosphotyrosine in Ig $\alpha$ places SLP65 in close vicinity to ITAMbound Syk and facilitates SLP65 phosphorylation (Engels et al, 2001; Kabak et al, 2002), which in turn augments $\mathrm{B}$-cell responses to $\mathrm{T}$ cell-independent antigens (Patterson et al, 2006). Nonetheless, Syk can phosphorylate SLP65 even in the absence of the non-ITAM tyrosine. It is unknown at what subcellular location this crucial step of signal initiation occurs and how the enzyme-substrate interaction is accomplished. However, genetic reconstitution experiments from our group provided evidence that the initiation of signalling requires protein complexes that are already formed before BCR stimulation (Wienands et al, 1996). Collectively, these examples suggest the existence of so far unidentified effector proteins of BCR signal initiation and processing.

To fill the gaps in our understanding of proximal BCR signalling, we have now determined the interactome of SLP65 in resting and stimulated B cells by quantitative mass spectrometry. Additional monitoring of the association kinetics revealed a class of steady ligands whose preformed association to SLP65 in resting cells remained unaltered upon BCR activation. One of those permanent SLP65 companions was the Cbl-interacting protein of $85 \mathrm{kDa}$ (CIN85) also named Ruk or SH3KBP1. Steady complex formation between CIN85 and SLP65 orchestrated Syk-mediated phosphorylation and membrane translocation of SLP65 and globally affected the composition of the SLP65 interactome. Mutational analysis showed that CIN85 is a novel key component of the BCRassociated transducer complex.

\section{Results}

\section{SILAC-based interactome analysis provides a library for the SLP65 signalling network}

To search for missing links of the primary BCR transducer complex, we determined the interactome of SLP65 using stable isotope labelling with amino acids in cell culture (SILAC) in combination with mass spectrometric analysis of affinity-purified protein complexes (Ong et al, 2002; Neumann et al, 2009; Selbach et al, 2009). Therefore, slp65 ${ }^{-/-}$DT40 B cells were reconstituted with an SLP65 variant harbouring an N-terminal One Strep tag that was expressed in almost identical amounts compared with endogenous SLP65 in wild-type cells (see Figure 1A). Cells expressing tagged SLP65 were cultured in SILAC medium containing lysine and arginine amino acids that have incorporated 'heavy' isotopes of carbon and nitrogen $\left({ }^{13} \mathrm{C}\right.$ and ${ }^{15} \mathrm{~N}$ ). As negative control, DT40 cells expressing non-tagged SLP65 were cultured in the presence of lysines and arginines encompassing carbon ${ }^{12} \mathrm{C}$ and nitrogen ${ }^{14} \mathrm{~N}$, so-called 'light' isotopes. Proteins from the two culture conditions contained either 'heavy' or 'light' lysines and arginines (Supplementary Figure S1). Accordingly, the two culture conditions confer distinct molecular masses on the cellular proteins synthesized; and thus, proteins derived from 'heavily' and 'lightly' labelled cells can be distinguished by mass spectrometry. For elucidation of the SLP65 interactome in the absence of BCR stimulation, the differentially labelled cells were lysed without further treatment. Proteins were affinity purified with a Strep-tactin column, pooled at a 1:1 ratio and hydrolysed with endoproteinase trypsin. Peptides were identified by liquid chromatography (LC)-coupled tandem mass spectrometry (MS/MS) and allocated to the corresponding protein by database search. Relative quantification of all sequenced peptides was performed using MaxQuant software (Cox et al, 2009) and is shown in Supplementary Table 1. An at least five-fold enrichment of heavy versus light peptides was considered to mark those proteins that were specifically copurified with One Strep-tagged SLP65 from resting cells. To identify inducible SLP65 interactors, we compared affinitypurified SLP65 complexes derived from 'lightly labelled' resting cells with those from 'heavily labelled' cells stimulated through their BCR for 2, 5, 10 or $20 \mathrm{~min}$.

In addition to previously reported SLP65 binders, a large number of unknown ligands were identified. Altogether, 29 proteins constituted the SLP65 interactome (Table I). Only a few ligand interactions existed in resting B cells, most notably to UNC119b implicated in the regulation of protein tyrosine kinase activity (Cen et al, 2003; Gorska et al, 2004) and to the SH3 domain-containing adaptor proteins Grb2, CIN85 and CD2-associated protein (CD2AP). CIN85 and CD2AP share a similar domain architecture encompassing three N-terminal SH3 domains followed by a proline-rich region and a C-terminal coiled-coil domain (Dustin et al, 1998; Take et al, 2000; Dikic, 2002). Since both adaptor proteins associate firmly and constitutively with actin-capping proteins $\mathrm{Z}$ (CapZ; Hutchings et al, 2003), the detection of CapZ isoforms as part of the SLP65 interactome in resting as well as stimulated B cells might be due to indirect co-purification of these cytoskeleton regulators. However, SLP65 appeared to possess several links to the cytoskeleton as also talin, profilin and Nck all implicated in actin filament dynamics (Buday et al, 2002; Le Clainche and Carlier, 2008) were identified as inducible ligands. Consistent with the role of SLP65 as upstream regulator of B-cell signalling cascades (Engelke et al, 2007), the inducible interactome accommodated positiveand negative-regulatory components of BCR-induced $\mathrm{Ca}^{2+}$ mobilization and MAP kinase activation. Finally, the C-type lectin 17A (CLEC17A) may contribute to SLP65 membrane recruitment as its cytoplasmic tail harbours binding sites for $\mathrm{SH} 2$ and $\mathrm{SH} 3$ domains. A glycan-binding protein with similar overall structure is also found in mammals and called prolectin (Graham et al, 2009).

\section{The association kinetics of individual SLP65 interactors defines distinct ligand classes}

Our description of the SLP65 interactome provided information about the ligands' identities and whether the corresponding complexes were dependent on BCR activation. However, this type of analysis does not take account of the dynamic nature of signal transduction processes as it lacks information about association kinetics. Thus, we quantified individual SLP65 ligands at different time points of BCR stimulation using a combined triple SILAC/MS approach with B cells that all expressed One Strep-tagged SLP65. Note that tagged SLP65 was expressed by the reconstituted cells in similar amounts compared with endogenous SLP65 in wild-type cells (Figure 1A). Cells were metabolically labelled in 'light' (Lys $+0 / \operatorname{Arg}+0)$, 'medium' (Lys $+4 / \operatorname{Arg}+6)$ or 'heavy' (Lys $+8 /$ Arg +10$)$ SILAC medium (see Materials and methods for details) and either left untreated or stimulated for 2 and 5, or 10 and $20 \mathrm{~min}$, respectively (see Figure $1 \mathrm{~A}$ ). Affinity-purified SLP65 complexes were mixed at a 1:1:1 
A
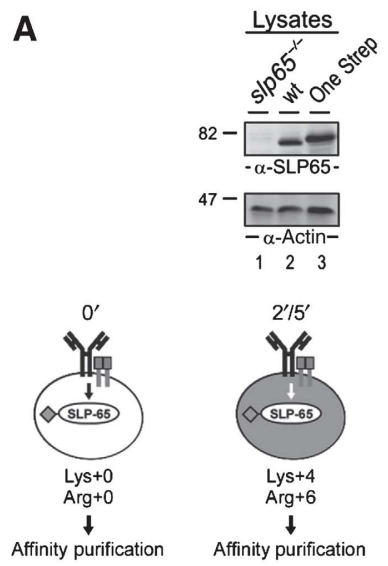

E

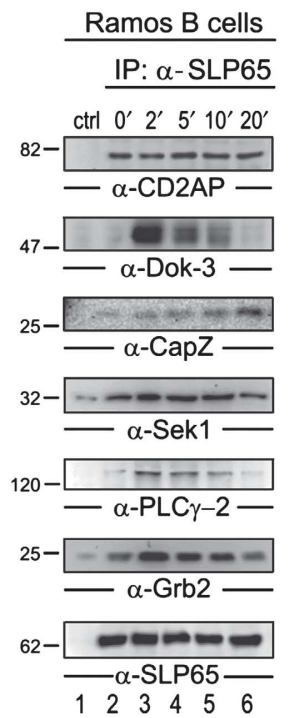

B
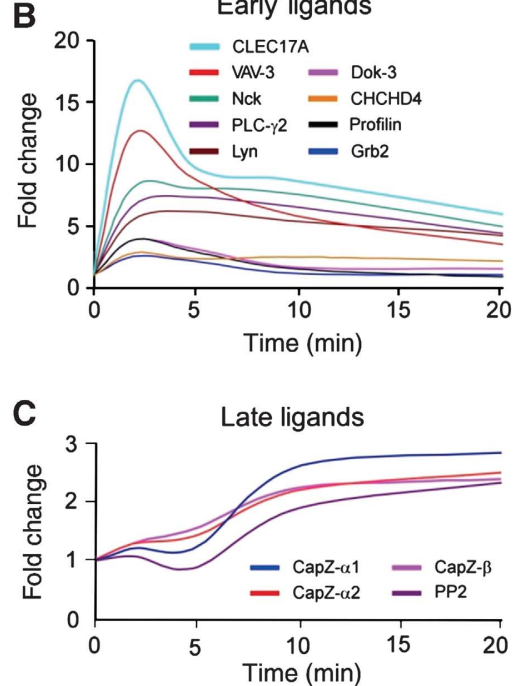

D

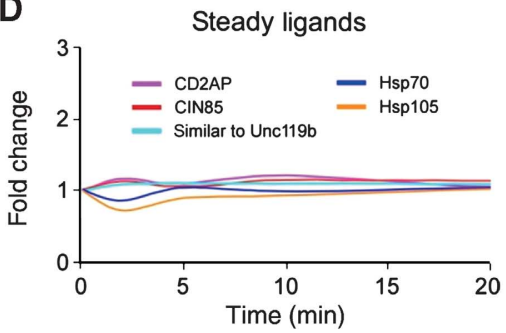

$\mathbf{F}$

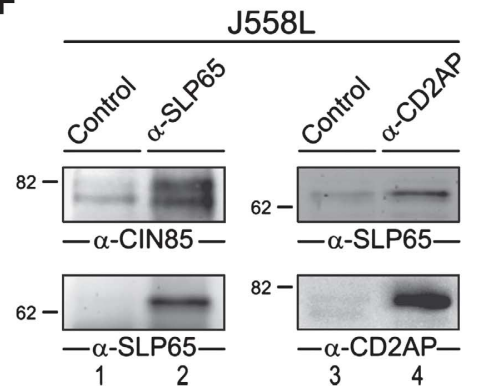

Figure 1 Association kinetics of SLP65 ligands. (A, top part) Immunoblot analysis with anti-SLP65 or anti-actin antibodies (upper and lower panels, respectively) of SLP65-negative DT40 B-cell mutants (lane 1), wild-type DT40 cells (wt, lane 2) and mutants cells that were reconstituted with One Strep-tagged SLP65 (lane 3) and provide the basis for all mass spectrometric ligand identification and quantification analysis. (A, bottom part) Schematic representation of a two-fold triple SILAC approach for relative quantification of individual SLP65 ligands under different stimulation conditions. DT40 B cells expressing One Strep-tagged SLP65 were cultured in SILAC medium containing the differentially labelled amino acids Lys $+0 / \operatorname{Arg}+0$ or Lys $+4 / \mathrm{Arg}+6$ or Lys $+8 / \mathrm{Arg}+10$. In a first approach, cells were left untreated or stimulated through their BCR for 2 or 20 min, respectively. In a complementary experiment to obtain continuous kinetics, cells were left untreated or BCR stimulated for 5 or $10 \mathrm{~min}$. From each approach, the affinity-purified SLP65 signalosomes were mixed at a 1:1:1 ratio. Ligands were identified and relatively quantified by LC-MS/MS using MaxQuant software. Note that not all interaction kinetics of SLP65 ligands could be measured owing to the increased sample complexity in our combined triple SILAC approach that reveals certain technical limitations of the MS instrument to detect low-abundant peptide pairs of ligands that only transiently or weakly interact with SLP65, for example, Btk and Syk. (B-D) The amounts of individual SLP65 ligands measured under distinct stimulation conditions were normalized according to the association quantity observed in resting cells (determined in both approaches). Subsequently, the mean values of the three independent doublet experiments were combined to a single time course of five different stimulation conditions as both sets contained quantitative interaction values from resting B cells which allowed for normalization of the data facilitated by the MaxQuant software. Based on this analysis, SLP65 ligands were classified as being early and transient (B), late and sustained (C) or steady (D). For detailed data sets and statistics, see Supplementary Table 2. (E) Human Ramos B cells left untreated (lanes 1 and 2) or BCR stimulated for 2, 5, 10 or 20 min (lanes 3-6) were lysed and subjected to immunoprecipitations with anti-SLP65 antibodies (lanes 2-6) or isotype-matched control antibodies (lane 1, ctrl). Obtained proteins were analysed by immunoblotting with antibodies directed against CD2AP, Dok-3, CapZ, Sek1/MAPKK4, PLC- $\gamma 2$ and Grb2 (upper to lower panel, respectively). (F) Lysates of BCR-negative J558L B cells were subjected to immunoprecipitations using antibodies to SLP65 (lane 2) or CD2AP (lane 4) or isotype-matched control antibodies (lanes 1 and 3). Obtained proteins were analysed by immunoblotting with antibodies recognizing CIN85 or SLP65 (lanes 1-2, upper and lower left panels, respectively), or SLP65 and CD2AP (lanes 3-4, upper and lower right panels, respectively). Relative molecular masses of marker proteins are indicated on the left in kDa. 
Table I The interactome of SLP65

\begin{tabular}{|c|c|c|c|}
\hline Ligand & IPI number & Function & References \\
\hline \multicolumn{4}{|l|}{ In resting $B$ cells } \\
\hline Grb2 & 00576615 & Adaptor protein & This study (Fu et al, 1998; Wienands et al, 1998) \\
\hline CIN85 & 00601097 & Adaptor protein & This study (Watanabe et al, 2000) \\
\hline CD2AP & 00583892 & Adaptor protein & This study \\
\hline CapZ- $\alpha 1$ & 00583945 & Cytoskeleton regulator & This study \\
\hline CapZ- $\alpha 2$ & 00582081 & Cytoskeleton regulator & This study \\
\hline CapZ- $\beta 1 / 2$ & 00591422 & Cytoskeleton regulator & This study \\
\hline Similar to Unc119b & 00584927 & Src kinase regulator & This study \\
\hline Hsp70 & 00582091 & Chaperone & This study \\
\hline Hsp105 & 00590633 & Chaperone & This study \\
\hline Ig heavy chain-binding protein & 00590375 & Chaperone & This study \\
\hline \multicolumn{4}{|l|}{ In activated $B$ cells } \\
\hline $\operatorname{Ig} \alpha(C D 79 A)$ & 00591677 & BCR component & This study (Engels et al, 2001) \\
\hline CLEC17A & 00599471 & Transmembrane lectin & This study \\
\hline Grb2 & 00576615 & Adaptor protein & This study (Fu et al, 1998; Wienands et al, 1998) \\
\hline CIN85 & 00601097 & Adaptor protein & This study (Watanabe et al, 2000) \\
\hline CD2AP & 00583892 & Adaptor protein & This study \\
\hline Dok-3 & 00845156 & Adaptor protein & This study \\
\hline Nck2 & 00599713 & Cytoskeleton adaptor & This study (Fu et al, 1998) \\
\hline CapZ- $\alpha 1$ & 00583945 & Cytoskeleton regulator & This study \\
\hline CapZ- $\alpha 2$ & 00582081 & Cytoskeleton regulator & This study \\
\hline CapZ- $\beta 1 / 2$ & 00591422 & Cytoskeleton regulator & This study \\
\hline Talin & 00586709 & Cytoskeleton regulator & This study \\
\hline Profilin & 00600305 & Cytoskeleton regulator & This study \\
\hline Similar to Unc119b & 00584927 & Src kinase regulator & This study \\
\hline Lyn & 00579414 & Protein tyrosine kinase & This study \\
\hline Syk & 00603504 & Protein tyrosine kinase & This study (Abudula et al, 2007; Kulathu et al, 2008) \\
\hline $\mathrm{Btk}^{\mathrm{a}}$ & 00595247 & Protein tyrosine kinase & This study (Hashimoto et al, 1999; Su et al, 1999) \\
\hline PLC- $\gamma 2$ & 00587921 & Phospholipase & This study (Fu et al, 1998) \\
\hline VAV3 & 00578220 & GTP exchange factor & This study (Fu et al, 1998; Wienands et al, 1998) \\
\hline Sek1/MAPKK4 & 00594829 & MAP kinase & This study \\
\hline Protein phosphatase 2 & 00651162 & Ser/Thr phosphatase & This study \\
\hline AIF (programmed cell death 8) & 00601063 & Apoptosis & This study \\
\hline Ig heavy chain-binding protein & 00590375 & Chaperone & This study \\
\hline Hsp70 & 00582091 & Chaperone & This study \\
\hline Hsp105 & 00590633 & Chaperone & This study \\
\hline WD repeat domain 81 & 00602009 & Unknown & This study \\
\hline $\mathrm{CCH}$ domain-containing 4 & 00574478 & Unknown & This study \\
\hline Hypothetical & 00602230 & Unknown & This study \\
\hline Hypothetical & 00597453 & Unknown & This study \\
\hline Hypothetical & 00813608 & Unknown & This study \\
\hline
\end{tabular}

Two independent SILAC-based LC-MS/MS analyses were performed for resting DT40 B cells and cells stimulated through their BCR for 2, 5, 10 and $20 \mathrm{~min}$. Detailed statistics including total number of all identified and quantified peptides as well as their significance and variability scores are shown in Supplementary Table 1. Listed proteins showed an at least five-fold enrichment of heavy versus light peptides.

${ }^{\mathrm{a}}$ The known ligand Btk co-migrated with the dominating protein band of Strep-tagged SLP65 and was thus less well detectable in this set-up but identified in a separate approach with GFP-tagged SLP65.

ratio (samples 0, 2, 20 and 0, 5, $10 \mathrm{~min}$ ) and identified as well as quantified as described above.

The relative association kinetics uncovered the dynamic nature of SLP65 complex formations and revealed three ligand classes. The class of early but transient interactors (Figure 1B) contained regulatory components of the $\mathrm{Ca}^{2+}$ flux pathway as well as Nck, Grb2 and CLEC17A. A second class of ligands characterized by a late and sustained association (Figure 1C) was represented by CapZ isoforms and the serine/threonine protein phosphatase 2 (PP2). Finally, we detected steady ligands whose association to SLP65 was almost unaffected by BCR engagement in that it was already 'preformed' before BCR activation and remained unchanged thereafter (Figure 1D). This class of constant SLP65 interactors contained CD2AP and CIN85. No BCR-induced loss of binding was observed. Co-immunoprecipitation experiments using human and murine B cells (Figure $1 \mathrm{E}$ and F) corroborated our proteomic results obtained in the avian system. Moreover, the constitutive association between SLP65 and
CIN85/CD2AP adaptors in BCR-negative J558L B cells (Figure $1 \mathrm{~F}$, left and right panels, respectively) showed that formation of these steady complexes was also independent of so-called 'tonic' BCR signalling in the absence of ligand (Monroe, 2006). In summary, quantitative monitoring of the association kinetics distinguished various classes of SLP65 ligands. Early interaction partners became rapidly engaged upon BCR stimulation and may generally reflect master regulators of BCR-proximal signalling pathways. Late interaction partners may be involved in signal processing. The function of the preformed and constant interactors was less obvious as they may act upstream or downstream of SLP65 or both.

\section{Steady ligands CIN85 and CD2AP bind atypical SH3-binding motifs of SLP65}

A stimulation-independent assembly of BCR effector proteins into preformed signalling complexes has been suggested as requisite for antigen-induced tyrosine phosphorylation of 
kinase substrates including SLP65 itself (Wienands et al, 1996, 1998). The identity and architecture of the preformed signalosomes remained unclear ever since. The steady SLP65 ligands CIN85 and/or CD2AP were candidate components as their multifunctionality has been implicated in several aspects of cell surface receptor biology (Dikic, 2002). We wanted to test this possibility by mutational analysis and mapped the interaction sites between SLP65 and CIN85/ CD2AP. SLP65 accommodates three evolutionary conserved proline/arginine-based docking motifs (Figure 2A) that match the previously reported atypical recognition consensus PXXXPR of the three SH3 domains of CIN85 and CD2AP (Kowanetz et al, 2003; Kurakin et al, 2003). Exchange of the critical arginine residue to alanine (R-to-A) within the three binding motifs abolished co-immunoprecipitation of SLP65 with both CIN85 and CD2AP from resting and BCR-activated $B$ cells (Figure 2B, left panel). Consistently, glutathione-S transferase (GST) fusion proteins encompassing the three SH3 domains of CD2AP or CIN85 affinity-purified wild-type SLP65 but not the triple R-to-A variant (Figure 2B, middle panel and data not shown). Hence, atypical proline/arginine motifs in SLP65 and the SH3 domains of CIN85/CD2AP were necessary and sufficient for steady complex formation in vivo. Binding studies with recombinantly expressed SLP65 and GST fusion proteins encompassing the triple $\mathrm{SH} 3$ domains of CIN85 confirmed that the interaction is direct (Figure 2B, right panel). Furthermore, the interaction is highly selective as shown by SILAC-based mass spectrometric determination of all putative PXXXPR ligands that exist in $\mathrm{B}$ cells. Figure $2 \mathrm{C}$ shows that biotinylated peptides encompassing the central proline/arginine motif of SLP65 almost exclusively purified CIN85 and CD2AP along with their intimate CapZ binding partners from B-cell lysates cultured in heavy SILAC medium. B cells that were cultured in light SILAC medium and subjected to affinity purification with a mutant form of the peptide served as control and for normalization of the binding scores. The only SH3 domain-containing protein that in addition to CIN85 and CD2AP showed a significant yet four-fold weaker binding score was Grb2. Hence, dependent on protein availability these sites may to some extent also bind Grb2. Collectively, these experiments demonstrated that assembly of the preformed SLP65 signalosome was based on the exquisite binding specificity of the atypical PXXXPR motifs which selectively recruited CIN85 and CD2AP.

\section{Steady ligands control the functionality and composition of the SLP65 interactome}

The functional role of the preformed SLP65 signalosome was assessed first in primary mouse B cells from which the endogenous proteins can be efficiently co-immunoprecipitated (Figure 3A, inlay of upper panel). Next, we retrovirally transduced splenic B cells from SLP65-deficient mice (Jumaa et al, 1999) to express citrine-tagged wild-type or triple R-to-A mutant SLP65. Equal expression of SLP65 proteins was confirmed by flow cytometric monitoring of the citrine fusion partner (data not shown). As shown in Figure 3A (upper panel), expression of wild-type but not mutant SLP65 reconstituted the BCR-induced $\mathrm{Ca}^{2+}$ response. Note that the weak $\mathrm{Ca}^{2+}$ flux profile elicited in B cells expressing the R-to-A mutant overlapped with that of SLP65-negative cells. Hence, ablation of CIN85/CD2AP binding to SLP65 generated a lossof-function mutant in splenic B cells. Similarly, BCR-induced
$\mathrm{Ca}^{2+}$ mobilization was blunted in DT40 B-cell transfectants expressing the triple R-to-A variant (Figure 3A, lower panel, purple and red curves). Single R-to-A exchanges in individual proline/arginine motifs (blue, brown and green curves) revealed a dominating role for the two $\mathrm{C}$-terminal docking sites, whose combined inactivation was sufficient to phenocopy the $\mathrm{Ca}^{2+}$ blockade of the triple mutant (light blue and purple curves) and to abolish binding to the SH3 domains of CIN85 and CD2AP (data not shown). To define the $\mathrm{Ca}^{2+}$ block, we analysed BCR-induced tyrosine phosphorylation of wild-type and mutant SLP65 as well as activation of PLC- $\gamma 2$. Loss of CIN85/CD2AP almost abrogated SLP65 phosphorylation (Figure 3B, left panels) and strongly compromised PLC- $\gamma 2$ activation as shown by anti-phosphotyrosine immunoblot analysis of anti-PLC- $\gamma 2$ precipitates (Figure 3B, right panels). Moreover, R-to-A mutant SLP65 was unable to promote activation of the NF- $\mathrm{BB}$ pathway (Figure $3 \mathrm{C}$ ). By contrast, Lyn and Syk were equally well phosphorylated on their activatory tyrosines in the presence of wild-type and mutant SLP65 (Figure 3D, left and right panels, respectively). Taken together, the preformed complex between CIN85/CD2AP adaptors and SLP65 is dispensable for linking the BCR to the activation of Lyn and Syk, but required for SLP65 phosphorylation and subsequent activation of $\mathrm{Ca}^{2+}$ and NF- $\kappa \mathrm{B}$ responses.

The functional deficits of R-to-A mutant SLP65 suggested a more general role of the steady complex for the SLP65controlled signalling network. To test this possibility in a comprehensive and quantitative manner, we modified our SILAC-based ligand screening and compared the stimulationdependent interactome of wild-type SLP65 with that of the triple R-to-A variant by 'reverse proteomics'. DT40 B cells expressing wild-type or mutant SLP65 were cultured in 'light' $($ Lys $+0 /$ Arg +0$)$ or 'heavy' (Lys $+8 /$ Arg +10$)$ SILAC medium, respectively. Following BCR stimulation of the cells for $2 \mathrm{~min}$, the interactomes of wild-type and mutant SLP65 were affinity purified and identified as described above. The amount of a given ligand purified with the R-to-A variant was normalized to that obtained with wild-type SLP65 (Figure 3E). Consistent with our previous results, no binding between mutant SLP65 and CIN85 or CD2AP was detected. Similarly, the association to the CIN85/CD2AP-associated CapZ isoforms was almost lost. Inactivation of the CIN85/ CD2AP binding sites in SLP65 also abrogated some but not all inducible interactions, for example to $\mathrm{Nck}$ or the $\mathrm{Ca}^{2+}$ regulators PLC- $\gamma 2$ and VAV3. By contrast, the R-to-A exchanges only moderately affected networking of SLP65 with other ligands such as CLEC17A, Dok-3 and profilin. Hence, loss of CIN85/CD2AP binding caused qualitative and quantitative changes in the composition of the SLP65 interactome. The data confirmed a more general upstream regulatory function of the preformed SLP65 signalosome and showed that our approach of 'reverse proteomics' elucidates putative effectors of a given protein-protein interaction in an unbiased manner.

\section{SLP65 and CIN85 constitute a proximal BCR transducer module}

The phosphorylation defect of the R-to-A variant demonstrated a disturbed kinase-substrate reaction between Syk and SLP65 that was likely to arise from local sequestration of the two proteins. In fact, it is unknown at what subcellular 


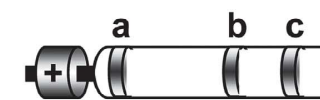

a

hUSLP 65 muSLP65

\section{SLP65}

b

C $\begin{array}{ll}{ }_{236} \text { SPPPAAPSPLPRAGKKPT }_{253} & { }_{301} \mathrm{KQIHQKPIPLPRFTEGGN} \\ { }_{237} \text { SSLPAAPSPLPRAGKKPA }_{254} & { }_{302} \mathrm{KPVHQKPVPLPRFPEAGS}_{319}\end{array}$

B

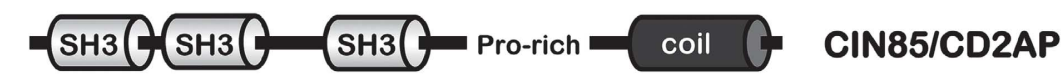

GST-
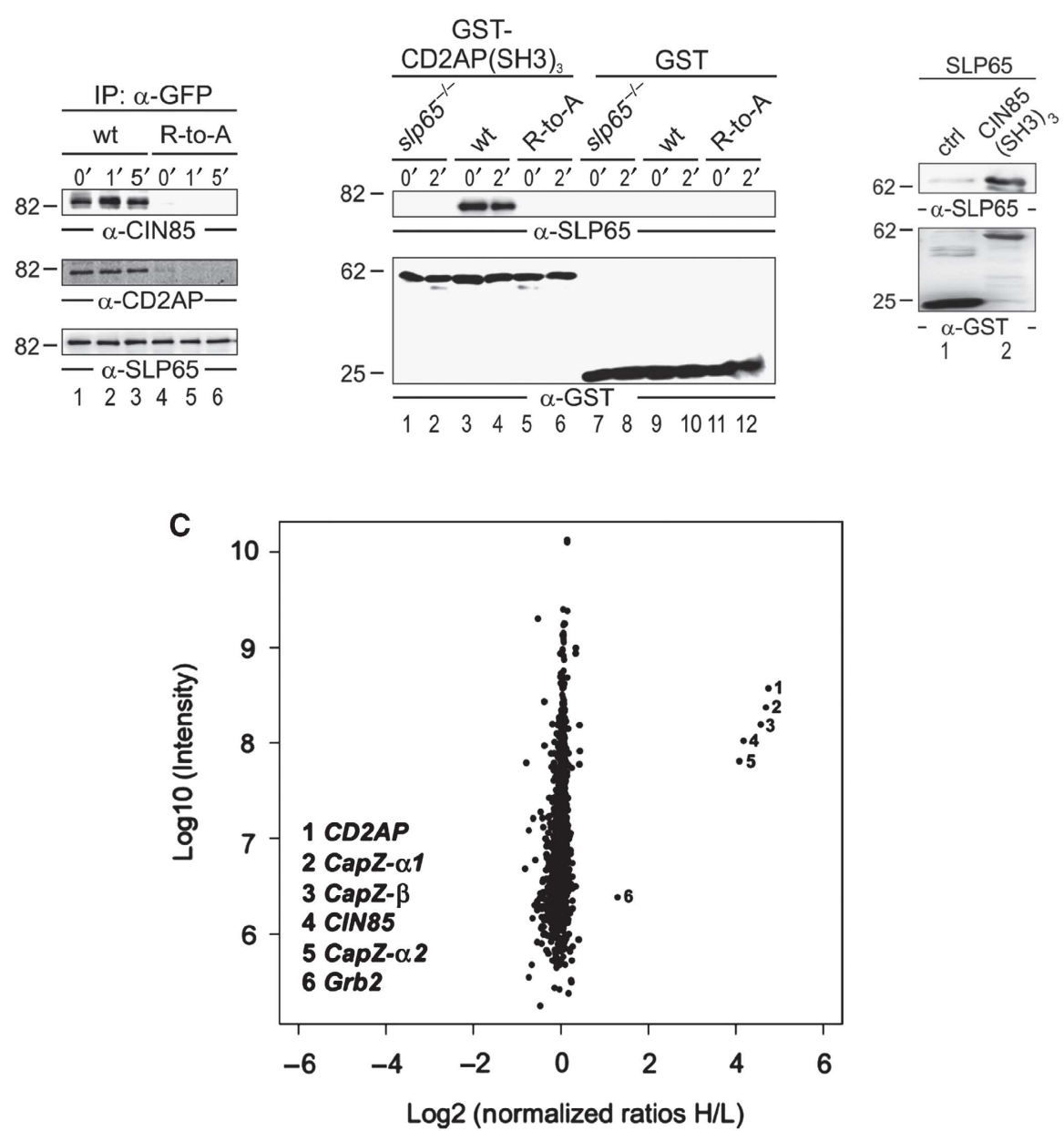

Figure 2 Atypical SH3 binding motifs of SLP65 selectively and directly recruit the steady ligands CIN85 and CD2AP. (A) Domain architecture of SLP65 and amino-acid sequences of the three atypical proline/arginine motifs (indicated by a-c) in human and murine SLP65. (B, top part) Domain architecture of CIN85/CD2AP adaptors. (B, bottom parts) SLP65-deficient DT40 B cells (slp65 ${ }^{-1}$ ) were reconstituted with green fluorescence protein (GFP)-tagged forms of either human wild-type SLP65 or a mutant version harbouring R-to-A amino-acid exchanges in all three atypical SH3 domain-binding motifs of the PXXXPR type (R49, 248 and 313A). Cells were left untreated $\left(0^{\prime}\right)$ or BCR stimulated for the indicated times in minutes (left and middle panels), and subjected either to immunoprecipitation (IP) with anti-GFP antibodies followed by immunoblot analysis of obtained proteins with antibodies recognizing CIN85, CD2AP or SLP65 (left panel, upper, middle and lower blots, respectively), or to affinity purifications using glutathione-S transferase (GST) fusion proteins encompassing the three SH3 domains of CD2AP $\left(\mathrm{GST}-\mathrm{CD} 2 \mathrm{AP}(\mathrm{SH})_{3}\right)$, or GST alone as negative control, followed by immunoblotting with antibodies recognizing SLP65 or GST (middle panel, upper and lower blots, respectively). Direct protein-protein interactions were tested in vitro by mixing recombinantly expressed HIS-tagged SLP65 with immobilized GST-CIN85(SH3) 3 , or immobilized GST alone as control, followed by immunoblot analysis of bound proteins with anti-SLP65 or anti-GST antibodies (right panel, upper and lower blots, respectively). Relative molecular masses of marker proteins are indicated on the left in $\mathrm{kDa}$. (C) DT40 B cells were metabolically labelled in heavy (Lys + 8/Arg + 10) SILAC medium and lysates were incubated with biotinylated peptides encompassing the central PXXXPR motif of human SLP65 (KSPPPAAPSPLPRAGKKPT). For control, DT40 B cells were cultured in light (Lys $+0 / \operatorname{Arg}+0$ ) SILAC medium and their lysates were incubated with biotinylated peptides, in which prolines at positions 10 and 13 were exchanged for alanine (KSPPPAAPSALPAAGKKPT). Purified proteins were mixed at a 1:1 ratio, digested with trypsin and identified by quantitative LC-MS/MS analysis using MaxQuant software. All identified proteins are plotted according to their 'heavy' versus 'light' ratio of enrichment (H/L) on logarithmic scales. Proteins with H/L ratio $>1$ are indicated, that is, CD2AP, CIN85, CapZ- $\alpha 1,-\alpha 2-,-\beta 1$ and Grb2. Complete list of proteins and statistics is listed in Supplementary Table 3. 
A
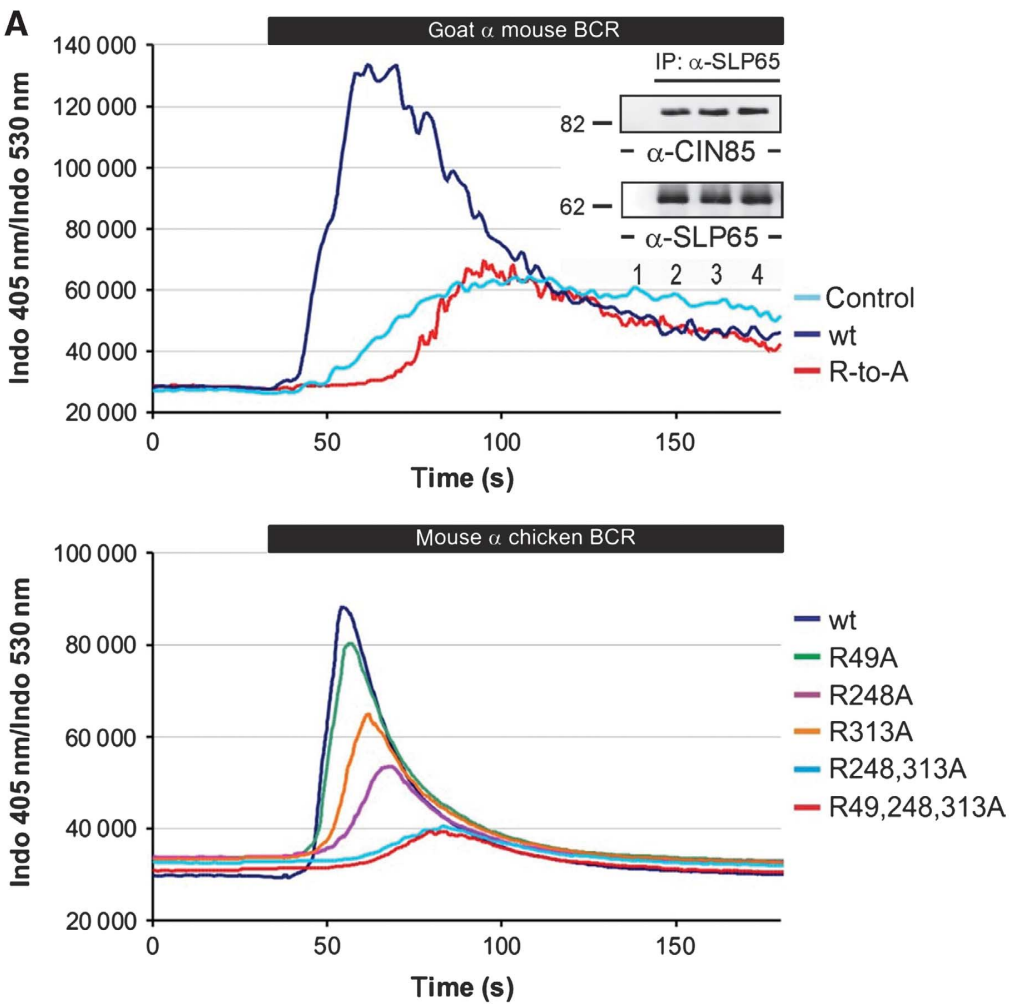

B

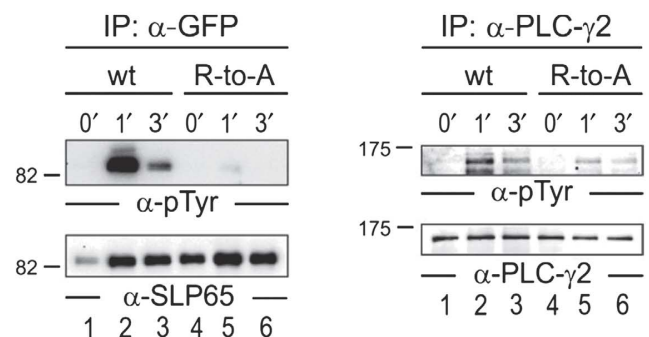

C

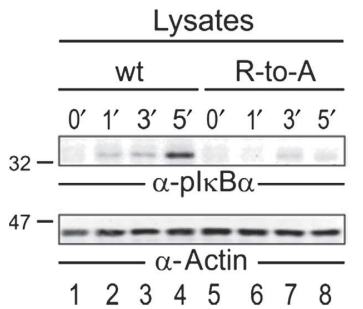

D

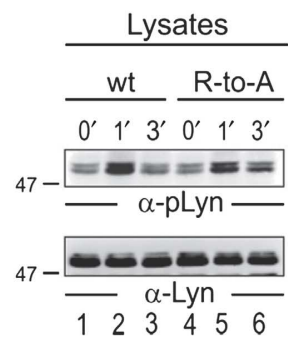

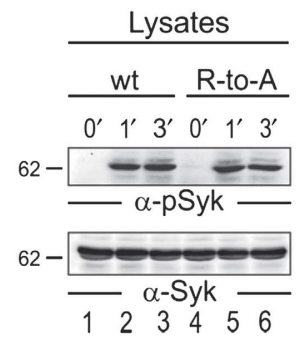

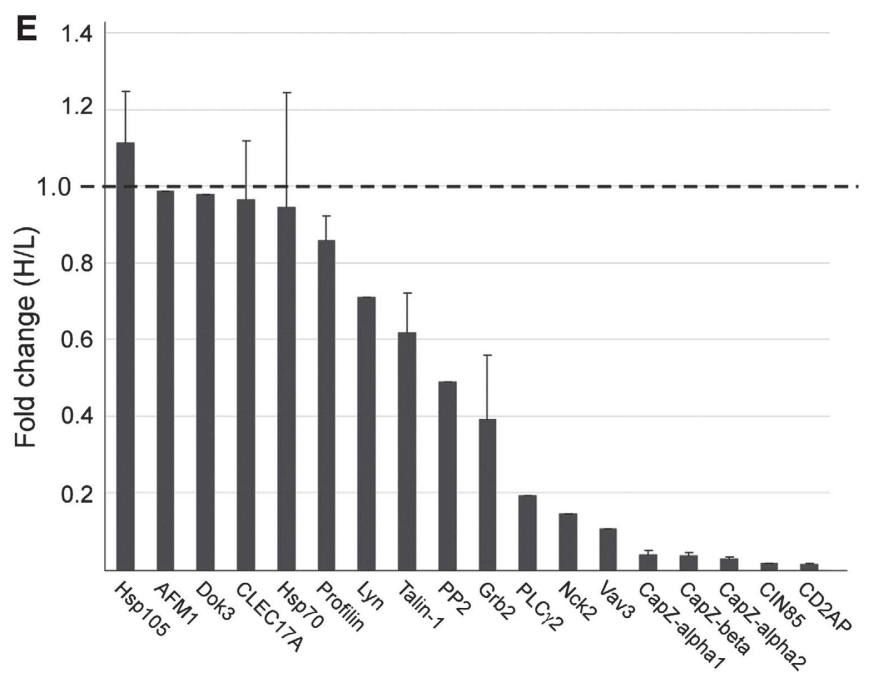

Figure 3 Loss of steady ligands abrogates SLP65 signalling functions. (A) Splenic B cells from slp65 ${ }^{-/-}$mice and SLP65-negative DT40 B cells (top and bottom panels, respectively) were reconstituted with wild type or indicated mutant forms of GFP-tagged human SLP65, loaded with the ratiometric $\mathrm{Ca}^{2+}$ chelator INDO-1-AM and subjected to BCR-induced $\mathrm{Ca}^{2+}$ flux analysis by flow cytometry. Inlay of top panel, lysates of primary B cells that were left untreated (lane 2) or BCR stimulated for 2 or 5 min (lanes 3 and 4 , respectively) were subjected to immunoprecipitation (IP) with anti-SLP65 antibodies (lanes 2-4) or irrelevant control antibodies, followed by immunoblot analysis of obtained proteins with antibodies recognizing CIN85 or SLP65 (upper and lower blots, respectively). Relative molecular mass of marker protein is indicated on the left in $\mathrm{kDa}$. (B-D) DT40 B cells expressing GFP-tagged wild type or triple R-to-A mutant SLP65 were left untreated or BCR stimulated for indicated times. Proteins obtained by anti-GFP or anti-PLC- $\gamma 2$ immunoprecipitations were analysed by anti-phosphotyrosine immunoblotting (B, upper left and right panels). Equal loading was confirmed by separate immunoblotting with antibodies recognizing SLP65 and PLC- $\gamma 2$ (lower left and right panels, respectively). Cleared cellular lysates were analysed by immunoblotting with phosphosite-specific antibodies against phosphoserine of IkB- $\alpha$, or the activatory phosphotyrosines of Lyn or Syk (C, D, upper left and right panels, respectively), and anti-actin, anti-Lyn and anti-Syk antibodies as loading controls (C, D, lower left and right panels, respectively). Relative molecular masses of marker proteins are indicated on the left in $\mathrm{kDa}$. (E) Bar diagram representing the quantitative changes in binding of individual ligands to the triple R-to-A mutant of SLP65 compared with wild-type SLP65 ('Reverse Proteome Analysis'). DT40 B cells expressing One Strep-tagged versions of wild-type or R-to-A mutant SLP65 were metabolically labelled in 'light' (Lys $+0 /$ Arg +0 ) or 'heavy' (Lys $+8 /$ Arg +10 ) SILAC medium, respectively. Following BCR stimulation of the cells for $2 \mathrm{~min}$, the interactomes of wild-type and mutant SLP65 were affinity purified and identified by quantitative LC-MS/MS analysis as described in Figure 1A. The amount of a ligand associated with wild-type SLP65 was set as 1. The relative increase or decrease in binding of ligands to mutant SLP65 is expressed as mean values of the fold change measured for the corresponding ratios of heavy versus light signal peaks in three independent experiments. Error bars represent standard deviations. For complete data set, see Supplementary Table 4. 

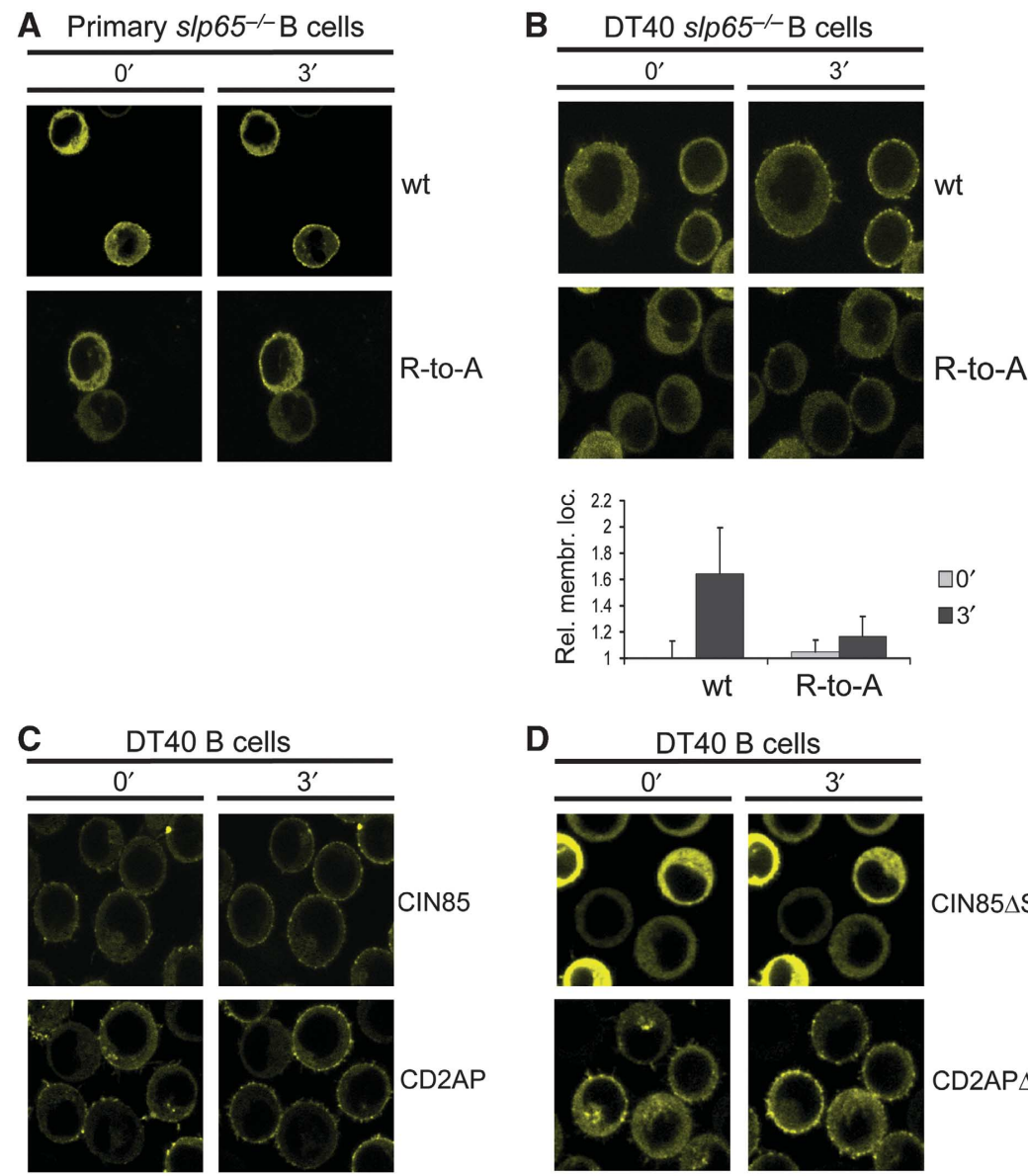

D
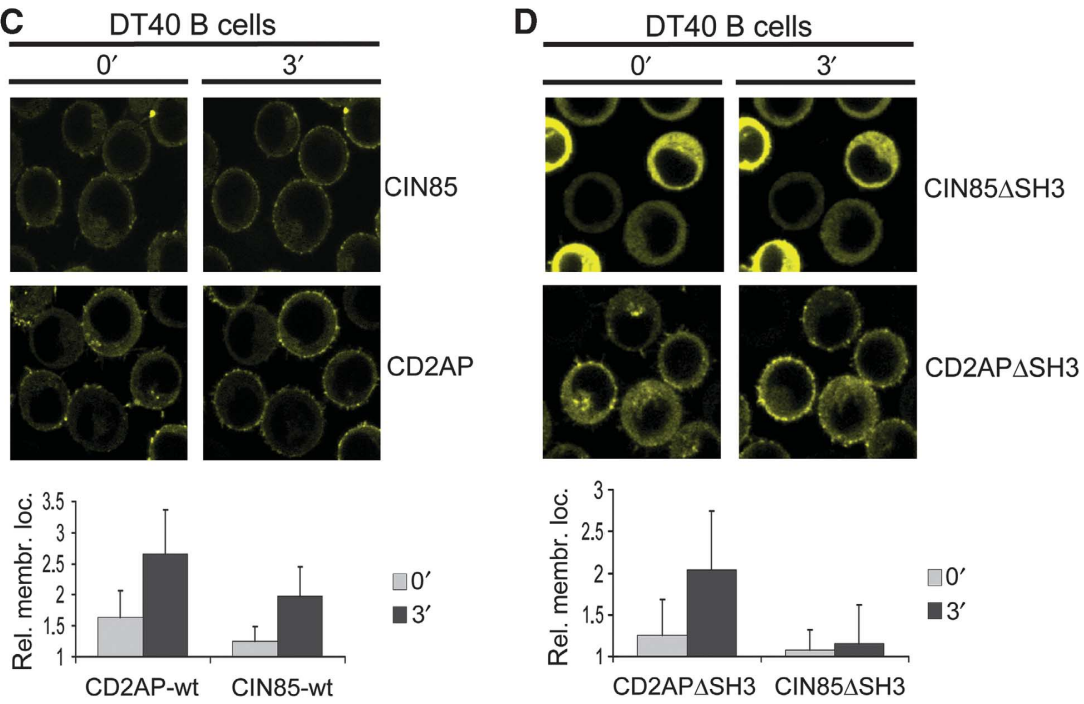

Figure 4 Steady ligands control inducible membrane translocation of SLP65. Confocal laser scanning microscopy of splenic B cells from slp65 $5^{-1-}$ mice (A) and SLP65-negative DT40 cells (B) expressing citrine-tagged versions of wild-type or R-to-A mutant human SLP65 (upper and lower images, respectively), and of DT40 B cells expressing citrine-tagged versions of wild-type human CIN85 or human CD2AP (C), or SH3 deletion mutants of CIN85 (CIN85 SH3, amino acids 329-665) or CD2AP (CD2AP $\Delta$ SH3, amino acids 330-639) (D) in the absence (left images) or presence (right images) of BCR ligation for the indicated times. Images of three independent experiments with DT40 B cells (B-D) were analysed with ImageJ to determine signal intensities in the cytosol and at the plasma membrane of at least 50 cells for each time point. Plotted values represent relative plasma membrane localization of the respective molecule calculated by the ratios of mean signal intensities in the cytosol to those at the plasma membrane, which were normalized to the ratios of cytosolic versus membrane-bound proteins in unstimulated cells. Error bars represent the $95 \%$ confidence interval. Despite the representative images obtained from primary B-cell transductants (A), a statistic quantification was not possible because the number of cells expressing citrine-tagged SLP65 was too low for two reasons. First, $\operatorname{slp} 65^{-/-}$mutant mice possess only few mature splenic B cells as a result of severely compromised B-cell development (Jumaa et al, 1999). Second, the efficiency of retroviral transduction experiments is generally weak and further reduces the number of cells, which are available for the microscopic analysis.

location that interaction takes place. To further investigate this aspect, we monitored the distribution of citrine-tagged SLP65 versions in primary mouse B cells and DT40 B cells by confocal laser scanning microscopy (Figure 4A and B, respectively). In both types of B cells, wild-type SLP65 quantitatively translocated from the cytosol to the plasma membrane in response to BCR activation (upper and lower panels, first row images). The R-to-A mutant was unable to relocate (upper and lower panels, second row images) even upon sustained B-cell stimulation (data not shown). This result indicated an active role for CIN85 or CD2AP in providing SLP65 with access to the plasma membrane where it meets
Syk. In support of this conclusion, a substantial amount of the cellular pools of CIN85 and CD2AP localized to the plasma membrane in resting $B$ cells which increased upon BCR ligation (Figure 4C). In case of CIN85, deletion of the three SH3 domains trapped the molecule in the cytosol (Figure 4D), while membrane recruitment of CD2AP was largely independent of the SH3 domains (lower panel, second row). Hence, wild-type CIN85 and CD2AP were both permanent membrane residents but possess different anchoring modes. This prompted us to visualize the exact localization of SLP65, CIN85 and CD2AP to the plasma membrane with improved effective resolution using total internal reflection 

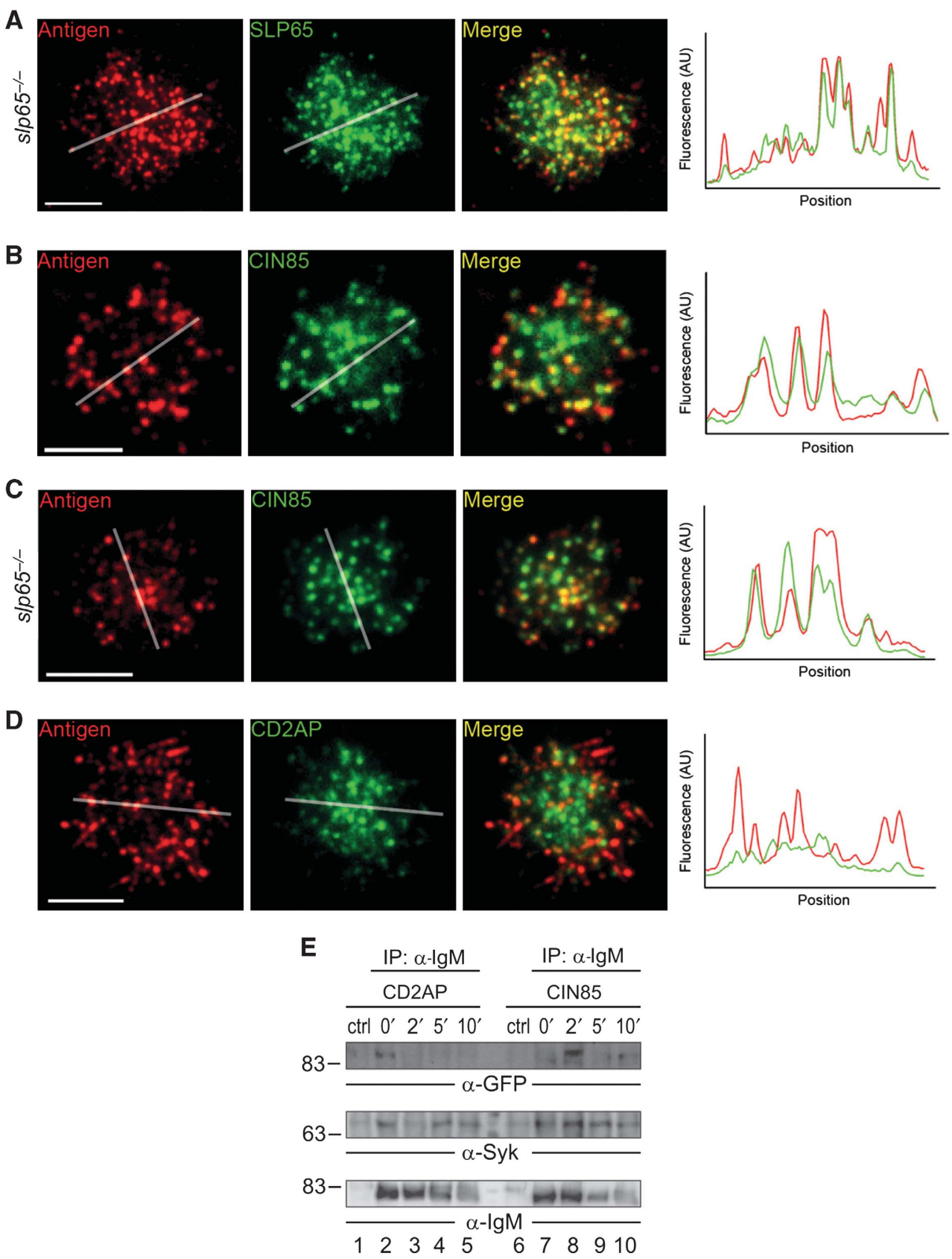

Figure 5 CIN85 colocalizes to BCR microclusters. DT40 B cell expressing GFP-tagged versions of SLP65 (A), CIN85 (B, C) or CD2AP (D) was settled on planar lipid bilayers containing $\sim 100$ molecules of RFP-labelled anti-IgM antibodies per $\mathrm{mm}^{2}$ and analysed by TIRF microscopy. Data were acquired for $12 \mathrm{~min}$ at one frame every $3 \mathrm{~s}$ (see Supplementary Movies 1-4). (E) DT40 B cells expressing citrine-tagged versions of CD2AP or CIN85 were left untreated or stimulated through their BCR for the indicated times and anti-IgM immunoprecipitates were subjected to immunoblot analysis with antibodies to GFP, Syk and IgM (lanes 2-10, upper, middle and lower panels, respectively). Protein A/G agarose beads served as control (ctrl, lane 1).

fluorescence (TIRF) microscopy. DT40 cells expressing citrine-tagged versions of either of the three proteins were settled on planar lipid bilayers loaded with RFP-labelled anti-IgM antibodies. Previously, it was shown that B cells on contact with anti-IgM-containing planar lipid bilayers undergo a rapid spreading and a more prolonged contraction response, resulting in the gathering of antigen in a central cluster for internalization (Fleire et al, 2006). Concomitant with spreading, numerous BCR-antigen microclusters are formed that recruit cytoplasmic signalling molecules amplifying the response and propagating B-cell spreading (Depoil et al, 2008; Weber et al, 2008). As shown in Figure 5A and Supplementary Movie 1, SLP65 colocalized to BCR microclusters during spreading, and remained localized to the central microcluster on completion of contraction. This is consistent with SH2-mediated binding of SLP65 to the nonITAM phosphotyrosine in Ig $\alpha$ (Engels et al, 2001; Kabak et al, 2002) and the requirement of SLP65 for the recruitment and retention of PLC- $\gamma 2$ at the BCR microcluster (Weber et al, 2008). Likewise, CIN85 colocalized to BCR microclusters following contact of the cells with anti-IgM-loaded lipid bilayers (Figure 5B; Supplementary Movie 2). Interestingly, 
the linkage of CIN85 with the BCR was independent of SLP65, as the distribution of CIN85 was not altered in B cells lacking SLP65 (Figure 5C; Supplementary Movie 3). Very few CD2AP molecules translocated into BCR microclusters (Figure 5D; Supplementary Movie 4). Hence, CIN85 rather than CD2AP may provide BCR-proximal transducer functions. Direct biochemical evidence for this conclusion was provided by robust co-immunoprecipitation of CIN85 with the activated BCR (Figure 5E, lanes 6-10). A weak interaction was also observed between $\mathrm{CD} 2 \mathrm{AP}$ and the BCR in resting cells (lanes 1-5).

\section{CIN85 is the functionally dominant SLP65 ligand but can be partially replaced by CD2AP}

To further decipher distinct versus redundant roles of CIN85 and CD2AP for SLP65 signalling, we generated $c d 2 a p^{-1-}$ DT40 B cells by gene targeting and used RNA interference to 'knock down' CIN85 expression in wild-type as well as $c d 2 a p^{-/-}$mutant B cells. Figure $6 \mathrm{~A}$ shows that lack of CD2AP expression (left panel) had no influence on the magnitude or duration of BCR-induced $\mathrm{Ca}^{2+}$ mobilization (right panel). In contrast, shRNA-mediated reduction of CIN85 expression caused a moderate but significant inhibition of $\mathrm{Ca}^{2+}$ fluxing (Figure 6B, left and right panels). When CD2AP deficiency was combined with reduced CIN85 expression the $\mathrm{Ca}^{2+}$ signal was strikingly diminished (Figure 6C, left and right panels). These results further demonstrated that CD2AP and CIN85 are no equal clients of SLP65. In the presence of CIN85, CD2AP seems to be dispensable for SLP65-controlled $\mathrm{Ca}^{2+}$ flux. However, CD2AP can partially compensate for reduced CIN85 levels in shRNA-treated DT40 B cells as only a combined deficit in the expression of both, CIN85 and CD2AP, had a major impact on the $\mathrm{Ca}^{2+}$ response. The residual $\mathrm{Ca}^{2+}$ signalling in the latter situation can be explained by the fact that RNA interference did not completely abolish CIN85 expression. It also remains possible that in the artificial situation when CD2AP and CIN85 are not at all or only weakly available other SLP65 ligands, for example, Grb2 (see above) may occupy the atypical SH3 domain-docking

A
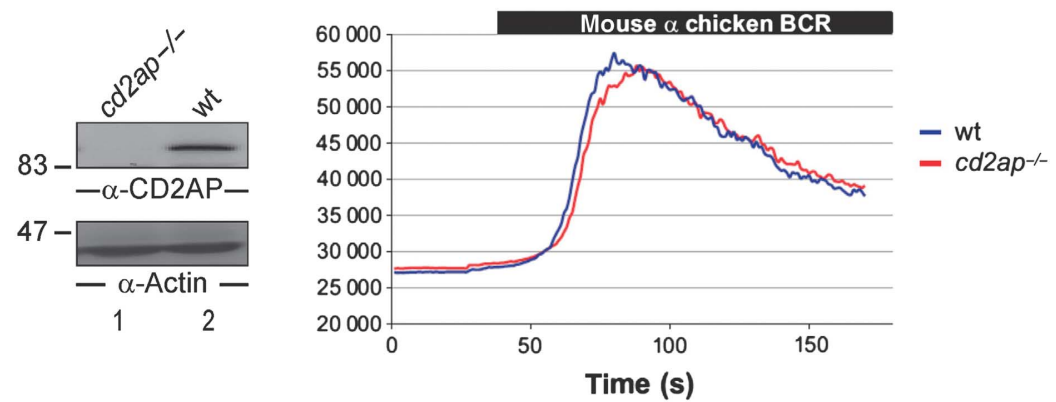

B
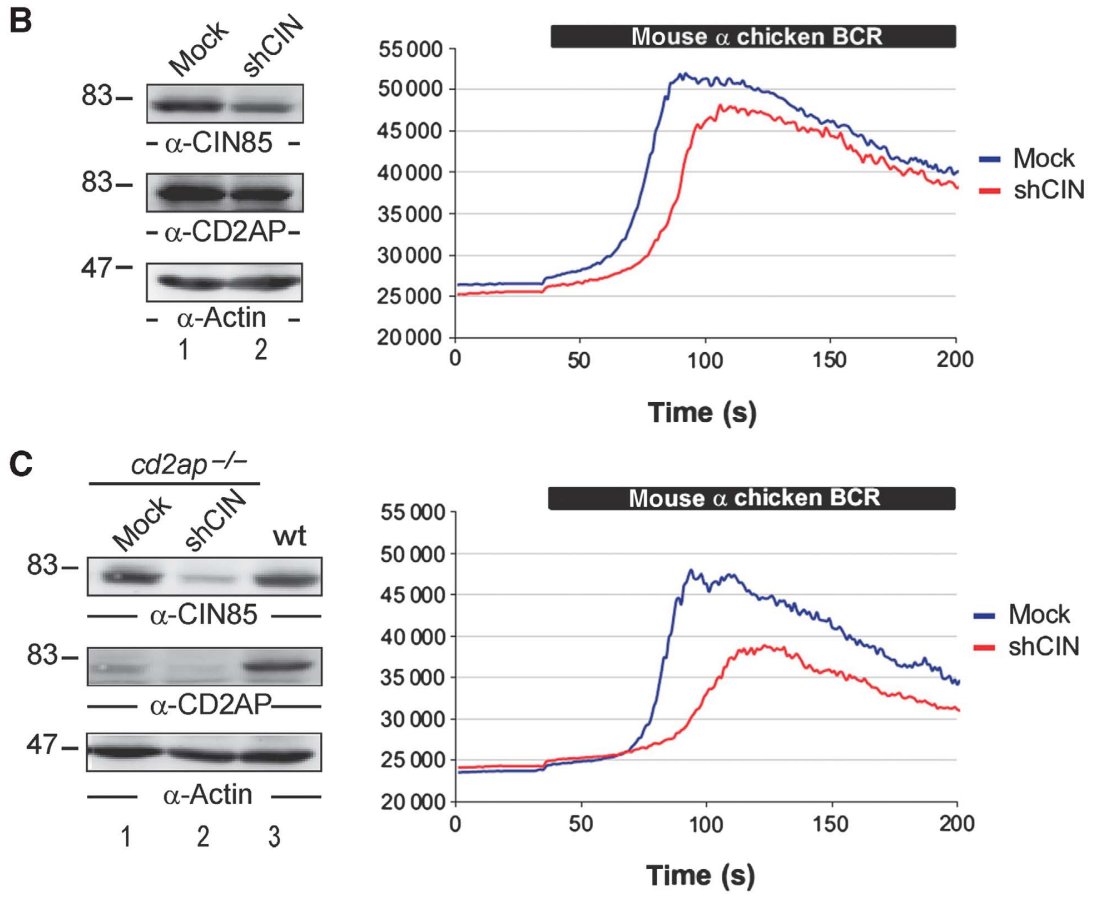

Figure $6 \mathrm{CD} 2 \mathrm{AP}$ compensates for reduced expression of CIN85. (A) CD2AP-deficient DT40 B cells were retrovirally transduced with a vector encoding citrine-tagged avian CD2AP or an empty control vector, and subjected to immunoblot analysis of lysates with antibodies to either $\mathrm{CD} 2 \mathrm{AP}$ or actin (left, upper and lower panels, respectively), or to ratiometric analysis of $\mathrm{Ca}^{2+}$ mobilization induced with $0.02 \mu \mathrm{g} / \mathrm{ml}$ mouse anti-IgM antibodies (right). (B, C) DT40 wild-type cells (B) or CD2AP-deficient mutants (C) were retrovirally transduced to express shRNA against CIN85 (shCIN) or control shRNA (mock). Cells were subjected to immunoblotting of lysates with antibodies recognizing CIN85, CD2AP or actin (left, upper, middle and lower panels, respectively), or to ratiometric $\mathrm{Ca}^{2+}$ analysis (right) as described in (A). Relative molecular masses of marker proteins are indicated on the left in $\mathrm{kDa}$. 
sites thereby supporting an SLP65 conformation that can be phosphorylated by Syk and is to some extent functional. However, our genetic approach to generate mutant $\mathrm{B}$ cells with modulated expression of CIN85 and/or CD2AP confirmed the important yet distinct roles of steady SLP65 ligands as integral components of the BCR transducer complex.

\section{CIN85 binding provides a subcellular localization signal} Binding of CIN85 to SLP65 can provide two principal functions. First, constitutive occupancy of the atypical $\mathrm{SH} 3$ domain-binding motifs acts as a structural determinant that holds SLP65 in a conformation which is accessible for Syk phosphorylation. Second, the C-terminal part of CIN85 provides a targeting signal that directs SLP65 into the proximity of the BCR and Syk. To directly test the second possibility, we engineered the three CIN85 binding sites of SLP65 into the T-cell adaptor SLP76 which lacks such motifs and whose inability to functionally substitute SLP65 in B cells has been explained by its mislocation and insufficient interaction to B-lymphoid effector proteins of the $\mathrm{Ca}^{2+}$ mobilization pathway (Ishiai et al, 2000; Wong et al, 2000). The sequence alignment in Figure 7A illustrates the amino-acid changes introduced into SLP76 at the three proline-rich motifs that correspond to the CIN85/CD2AP binding sites in SLP65. A GFP-tagged version of the engineered SLP76 variant (termed SLP76*) was expressed in SLP65-deficient B cells and tested for its capability to communicate with the BCR signalling machinery. Similar to SLP65 but in contrast to wild-type SLP76, SLP76* associated constantly with CIN85 and became efficiently tyrosine phosphorylated although with a delayed kinetic (Figure 7B, left and right panels, respectively). Importantly, SLP76*-expressing B cells mounted a robust $\mathrm{Ca}^{2+}$ response (Figure 7D). Inducible translocation into plasma membrane speckles was observed for SLP76* but not for wild-type SLP76 (Figure 7E). In summary, when equipped with the CIN85 binding sites of SLP65, the T-cell adaptor SLP76 complemented SLP65 deficiency of B cells. This provides direct evidence that CIN85 regulates the subcellular localization of SLP adaptors in addition to a possible impact of CIN85 binding on the conformation of SLP65.

\section{Discussion}

It is well documented that a concerted action of Syk and SLP65 initiates BCR signal transduction. Phospho-ITAMs in the Ig $\alpha \beta$ heterodimer provide a physical link between the activated BCR and Syk, and simultaneously enhance the catalytic activity of Syk by allosteric regulation (Engels et al, 2008). By contrast, the interaction mode between Syk and SLP65 was unclear as the subcellular targeting mechanisms of SLP65 remained enigmatic. In the present report, we have elucidated the SLP65 interactome and monitored the association kinetics by relative quantification of individual complex formations for various stimulation periods. This allowed for the classification of SLP65 ligands into three different groups, that is, early and transient interactors, late

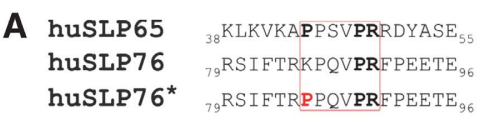

B

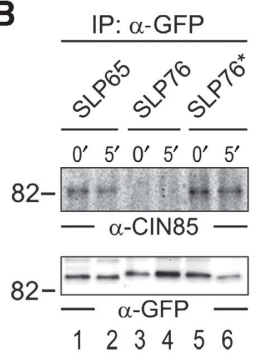

D

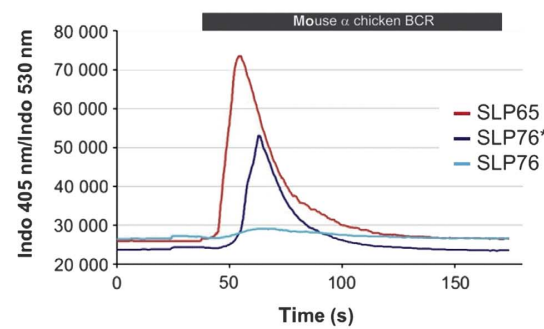

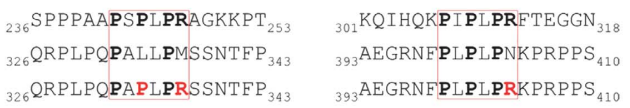

C

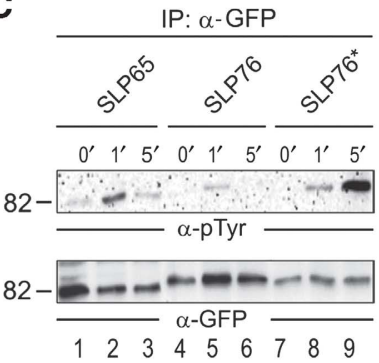

E

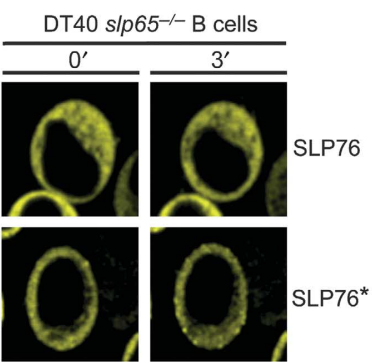

Figure 7 T-cell SLP76 functions in B cells when equipped with CIN85 binding sites. (A) Amino-acid sequence alignment of corresponding SH3 domain-binding sites in human SLP65, SLP76 and SLP76*. Conserved proline and arginine residues are in black bold letters. The atypical proline/arginine motifs are boxed. Genetically engineered amino-acid exchanges are marked in bold red. (B, C) SLP65-negative DT40 B cells were reconstituted with GFP-tagged versions of wild-type SLP65, wild-type SLP76 or variant SLP76 accommodating three CIN85 binding sites shown in (A). Cells were left untreated $\left(0^{\prime}\right)$ or BCR stimulated for the indicated times in minutes $\left(1^{\prime}\right.$ and $\left.5^{\prime}\right)$ and SLP adaptors were immunoprecipitated with anti-GFP antibodies. Obtained proteins were analysed by immunoblotting with antibodies to CIN85 (B, upper panel), GFP (B, C, lower panels) or phosphotyrosine (C, upper panel). Relative molecular masses of marker proteins are indicated on the left in kDa. (D, E) Cells described in (A) were subjected to BCR-induced $\mathrm{Ca}^{2+}$ flux analysis by flow cytometry using INDO-1-AM (D) and confocal laser scanning microscopy in the absence and presence of BCR stimulation for 3 min to visualize subcellular localization of SLP adaptors (E). 
and sustained interactors, and steady interactors which continuously associate with SLP65 at a constant level. Members of the first two groups mainly contained master regulators of BCR-proximal signalling pathways and response modulators involved in signal integration and processing. The function of the steady binding partners was less obvious, but their stimulation-independent and non-dynamic association to SLP65 was consistent with the functional properties of a preformed BCR transducer complex that was predicted based on genetic evidence and explained the efficient coupling of BCR-proximal effector molecules (Wienands et al, 1996). Indeed, steady complex formation of SLP65 with CIN85 and/or CD2AP constitutes a functional unit as demonstrated by proteomic and biochemical studies followed by the mutational analyses in cultured and primary B cells, and finally confocal and TIRF microscopy. The pivotal role of the SLP65/CIN85 signalling module for humoral immunity is demonstrated by almost abrogated T-independent type II antibody responses in mutant mice with $\mathrm{B}$ cell-specific ablation of CIN85 expression (Kometani and Kurosaki, 2011). In direct accordance with our data, CIN85-deficient B cells failed to activate the NF- $\kappa \mathrm{B}$ pathway in response to BCR ligation, while the response to other stimuli such as anti-CD40, BAFF or Il-4 was normal. These data further support the role of CIN85 as a positive and specific signal effector of the BCR.

Our mass spectrometric elucidation of the SLP65 interactome circumvented common disadvantages associated with conventional approaches to characterize protein complexes, for example, weak signal-to-noise ratios, loss of binding partners owing to antibody-mediated complex disruption and in vitro enrichment of false positive candidates. The SLP65 interactors listed in Table I showed an at least fivefold enrichment of heavily versus lightly labelled peptides. This threshold is rather high compared with other SILACbased studies, where the significance for ligand identification was defined by an enrichment factor of 2.5 or 3 (Ong et al, 2002; Selbach et al, 2009). Thus, our collection unambiguously represents in vivo ligands but some additional interactors may be verified by future experiments. Nonetheless, the large number of 29 identified ligands strongly suggests the existence of distinct subcellular pools of SLP65, which individually participate in the assembly of structurally and functionally diverse complexes. This conclusion is further supported by the highly complex and dynamic usage of $>40$ phosphoacceptor sites in SLP65 (Oellerich et al, 2009) and the fact that the identified ligands execute positive as well as negative-regulatory functions in a broad variety of BCRinduced signal pathways such as $\mathrm{Ca}^{2+}$ mobilization, activation of MAP kinases, regulation of apoptosis and remodelling of the actin cytoskeleton (see Table I). Moreover, the function of several SLP65 binding partners remains to be elucidated. Altogether, our data provide a basis to explain how SLP65 collects and processes BCR signals as a genuine signal integrator.

SILAC-based quantification of ligand interactions revealed dynamic networking of SLP65 with most of its ligands. Noteworthy, no BCR-triggered loss of SLP65 binding partners was observed which would have indicated signal-induced release of SLP65 inhibitory proteins. Only a small number of steady SLP65 ligands existed including CIN85 and CD2AP which constitute a family of multifunctional scaffolding proteins. Three atypical proline/arginine motifs of the PXXXPR type (Kowanetz et al, 2003; Kurakin et al, 2003) in SLP65 provided highly selective docking sites for the three $\mathrm{SH} 3$ domains of CIN85 and CD2AP. Inactivation of the docking sites by R-to-A exchanges and concomitant loss of CIN85/ CD2AP adaptors caused fundamental signalling deficits in DT40 and primary B cells. The mutation reduced the complexity of the SLP65 interactome, blocked the BCR-proximal substrate interaction with activated Syk and abrogated SLP65 membrane translocation that altogether abolished $\mathrm{Ca}^{2+}$ and $\mathrm{NF}-\kappa \mathrm{B}$ responses. In conclusion, the ability of SLP65 to form a steady complex with CIN85/CD2AP adaptors is a critical determinant for the functionality of the BCR transducer complex. Microscopic imaging directly supported this result but also suggested that CIN85 is closer associated with BCR microclusters than CD2AP. In fact, intracellular navigation and BCR colocalization of SLP65 were identical to that of CIN85 but significantly different to the trafficking properties of $\mathrm{CD} 2 \mathrm{AP}$. It is, therefore, likely that the BCR transducer module utilizes predominantly CIN85 rather than CD2AP for linking Syk activation to SLP65 phosphorylation. This model is supported further by our gene targeting and RNA interference experiments. They also revealed that functional redundancy is nonetheless possible as occupancy of the proline/arginine motifs by CIN85 can serve at least two functions. Docking of the N-terminal SH3 domains confers a conformation to SLP65 that is accessible for Syk, while the C-terminal part of CIN85 provides a subcellular targeting signal. Depending on protein availability, the former function might be partially substituted by $\mathrm{SH} 3$ domains of alternative binding partners such as Grb2 to allow for residual $\mathrm{Ca}^{2+}$ mobilization in our CIN85/CD2AP-compromised cells. However, in the presence of CIN85 and CD2AP, Grb2 is dispensable for SLP65 phosphorylation (Stork et al, 2004, 2007). Direct evidence for the potent signalling and targeting function of the CIN85 binding sites is provided by the ability of the T-cell adaptor SLP76 to respond to BCR activation when equipped with the PXXXPR motifs.

CIN85 may utilize several mechanisms for subcellular targeting of SLP65. Direct association of CIN85 to phosphatidic acid (Zhang et al, 2009) in concert with the membrane binding and bending activities of known CIN85 binding partners (Havrylov et al, 2010) could link SLP65 to signalling-competent membrane microdomains. Likewise, the $\mathrm{Cbl}$ family of E3 ubiquitin ligases may provide a targeting function by simultaneous binding to CIN85 and BCR-associated Syk. In support of this possibility ablation of both $\mathrm{Cbl}$ and Cbl-b expression in B cells almost abrogated SLP65 tyrosine phosphorylation (Kitaura et al, 2007). Finally, precise subcellular targeting of the CIN85/SLP65 transducer module may also involve complex regulatory circuits of cytoskeleton reorganization. This is suggested by the large number of cytoskeleton regulators associated with CIN85/CD2AP (Dikic, 2002; Havrylov et al, 2010) as well as SLP65 (see Table I) and the more recently reported impact of actin-defined networks on early BCR signalling (Treanor et al, 2010). Additional interactions of SLP65 to Ig $\alpha$ (Engels et al, 2001) or accessory transmembrane proteins might stabilize the complex. In summary, our interactome analysis demonstrated that SLP65 acts as core structural organizer for early and late BCR signalling responses and identified the family of CIN85/CD2AP adaptors as missing link for subcellular targeting of a preformed BCR transducer complex. 


\section{Materials and methods}

Cells, antibodies and reagents

Wild-type and SLP65-deficient DT40 B cells were cultured, stimulated and lysed as described (Oellerich et al, 2009). Ramos B cells were activated with $8 \mu \mathrm{g} / \mathrm{ml}$ of $\mathrm{F}\left(\mathrm{ab}^{\prime}\right)_{2}$-anti-human IgM at $37^{\circ} \mathrm{C}$. Human SLP65, SLP65-GFP fusion proteins and PLC- $\gamma 2$ were immunoprecipitated from lysates of 2 to $3 \times 10^{7}$ B cells with antibodies recognizing SLP65 (Cell Signaling Technology/BD Biosciences), GFP (Roche) or PLC- $\gamma 2$ (Santa Cruz) coupled to protein A/G sepharose (Pierce). Immunoprecipitations with J558L cells were performed using anti-CD2AP (Santa Cruz) or rabbit polyclonal anti-SLP65 (anti-KARLA; Wienands et al, 1998) antibodies. The stimulated chicken IgM-BCR was immunoprecipitated from the cell surface of $3 \times 10^{7}$ DT40 B cells by incubation of the cells with $2 \mu \mathrm{g} / \mathrm{ml}$ mouse anti-chicken IgM (M4, Bethyl) for various time points at $37^{\circ} \mathrm{C}$ and subjecting the cleared cellular lysates for $1 \mathrm{~h}$ to incubation with goat anti-mouse antibodies (Southern Biotech) immobilized Protein A/G sepharose. To precipitate the resting BCR incubations were performed on ice. Antibodies for immunoblot analyses were used according to manufacturer's instructions and recognized SLP65, CD2AP, Grb-2, Sek1, Syk, phosphorylated Syk and Lyn (all Cell Signaling Technologies/BD Biosciences), CapZ and Dok-3 (Santa Cruz), CIN85 (Sigma), GFP (Roche) and GST (Molecular Probes), chicken IgM (Bethyl) and phosphotyrosine (4G10, Biomol). GST-CD2AP(SH3) ${ }_{3}$ fusion proteins were expressed in BL21(DE3) bacteria upon induction with $0.1 \mathrm{mM}$ IPTG for $3 \mathrm{~h}$ and immobilized on Glutathione-Sepharose ${ }^{\mathrm{TM}}$ 4FastFlow (GE Healthcare). Primary splenic murine B cells were isolated using B-cell isolation kit (Miltenyi Biotech).

\section{Vectors, transfections and retroviral transductions}

The cDNAs encoding human, murine or chicken SLP65 or human SLP76 tagged on their C- or N-terminus with either EGFP or citrine were ligated into pCRII-Topo. These plasmids were used to generate triple R-to-A mutants of SLP65 (R49, 248 and 313A), or the SLP76* variant accommodating the CIN85 binding sites (K85P, L334P, M337R and N404R) by site-directed mutagenesis (Quikchange). Resulting cDNA fragments were inserted into the pMSCV vector (BD Biosciences, USA) for retroviral transduction of SLP65-deficient DT40 and primary B cells as described (Engels et al, 2009). The cDNAs encoding N-terminally One Strep-tagged forms of chicken or human SLP65 and its triple R-to-A variant were ligated into pAbespuro and transfected as described (Oellerich et al, 2009). From each transfection, three independent clones that expressed SLP65 proteins to similar amounts than wild-type DT40 cells were pooled and used for further experiments. Deletion variants of human CD2AP and human CIN85 were generated by PCR yielding cDNAs coding for CD2APASH3 (amino acids 330-639) or CIN85 $\Delta \mathrm{SH} 3$ (amino acids 329-665). N-terminally citrine-tagged cDNAs were ligated into the pMSCV vector for retroviral transduction. PCR products encoding the three $\mathrm{SH} 3$ domains of $\mathrm{CD} 2 \mathrm{AP}$ (amino acids 1-330) or CIN85 (amino acids 1-328) were ligated into pGEX-4T-1 (Amersham Biosciences), and the corresponding GST fusion proteins were produced in BL21 bacteria upon induction with $0.1 \mathrm{mM}$ IPTG. When used for in vitro binding studies GST-CIN85(SH3) fusion proteins were mixed with full-length SLP65 purified through its N-terminal histidine (HIS) tag. BCR-induced $\mathrm{Ca}^{2}+$ mobilization was monitored on an LSR II cytometer (Becton Dickinson) as described (Engels et al, 2009). Targeted disruption of $c d 2 a p$ alleles in DT40 B cells was achieved with vectors that introduced a stop codon $3^{\prime}$ of the third codon of exon 3 and replaced the rest of exon 3 with either blasticidin or histidinol (HisD) resistance cassettes. Primer sequences for amplification of genomic fragments $5^{\prime}$ and $3^{\prime}$ of exon 3 (2.55 and $2.5 \mathrm{~kb}$, respectively) are available on request. Following electroporation of targeting constructs, cells were selected using $0.5 \mathrm{mg} / \mathrm{ml} \mathrm{HisD}$ and $30 \mu \mathrm{g} / \mathrm{ml}$ blasticidin. Retroviral vectors for interference with CIN85 expression in chicken $\mathrm{B}$ cells encompassed an shRNA template oligonucleotide in which the target CIN85 sense and antisense sequence was flanked by miR-30 miRNA sequences. Additionally, an miR-30 loop sequence was inserted between the sense and antisense sequence. CIN85 shRNA or the control oligonucleotide (exact sequences are available on request) was ligated $5^{\prime}$ of the IRES-GFP cassette in the MSCV-LMP retroviral vector (Open Biosystems). Transductants were selected with $1 \mu \mathrm{g} / \mathrm{ml}$ puromycin.

\section{Affinity purification of SLP65 signalosomes from SILAC-labelled cells}

Metabolic labelling via SILAC was performed as described (Oellerich et al, 2009). For determination of the SLP65 interactome, DT40 B cells expressing One Strep-tagged SLP65 were cultured in heavy SILAC medium containing ${ }^{13} \mathrm{C}_{6},{ }^{15} \mathrm{~N}_{2}$-Lys (Lys +8 ) and ${ }^{13} \mathrm{C}_{6},{ }^{15} \mathrm{~N}_{4}$-Arg (Arg +10$)$, whereas cells expressing non-tagged SLP65 were cultured in light SILAC medium containing ${ }^{12} \mathrm{C}_{6},{ }^{14} \mathrm{~N}_{2}-$ Lys and (Lys +0$){ }^{12} \mathrm{C}_{6},{ }^{14} \mathrm{~N}_{4}$-Arg (Arg +0$)$. For affinity purification of SLP65 signalosomes, $2 \times 10^{8}$ cells expressing tagged or nontagged SLP65 and labelled in heavy (Lys $+8 / \operatorname{Arg}+10$ ) or light $($ Lys $+0 / A r g+0)$ SILAC medium were stimulated through their BCR for indicated times and lysed as described (Oellerich et al, 2009). Protein concentrations of the lysates were determined and normalized amounts of lysates of the differentially labelled cells were incubated with $200 \mu$ of Strep-Tactin Superflow matrix (Iba BioTagnologies) for $1 \mathrm{~h}$ at $4^{\circ} \mathrm{C}$. For each approach, $500 \mu \mathrm{l}$ desthiobiotin buffer (Iba BioTagnologies) was used to elute purified proteins at room temperature. Eluates were pooled in a 1:1 ratio, concentrated in ultrafiltration spin columns (Sartorius, Göttingen) and proteins were separated by 1-D polyacrylamide gel electrophoresis. For monitoring SLP65 association kinetics, DT40 B cells expressing One Strep-tagged SLP65 were split into three batches and cultured in light $($ Lys $+0 / \operatorname{Arg}+0)$ or heavy (Lys $+8 / \operatorname{Arg}+10)$ SILAC medium or in medium heavy (Lys $+4 / A r g+6)$ medium containing ${ }^{2} \mathrm{D} 4,{ }^{12} \mathrm{C} 6,{ }^{14} \mathrm{~N} 2$-Lys (Lys +4$)$ and ${ }^{13} \mathrm{C} 6,{ }^{14} \mathrm{~N} 4$-Arg (Arg + 6). Lightly labelled cells were left untreated, medium heavily labelled cells were stimulated through their BCR for 2 or $5 \mathrm{~min}$ and heavily labelled cells were stimulated for 10 or $20 \mathrm{~min}$. Following lysis and affinity purification of SLP-65 (see above), eluates were pooled at a 1:1:1 ratio in two combinations: first, with eluates obtained from cells that were stimulated for 0 min (light), 2 min (medium heavy) or $20 \mathrm{~min}$ (heavy); and second, from cells stimulated for $0 \mathrm{~min}$ (light), $5 \mathrm{~min}$ (medium heavy) or $10 \mathrm{~min}$ (heavy). For analysing the impact of the triple R-to-A mutation on the composition of the SLP65 interactome ('reverse proteomics'), DT40 B cells expressing Strep-tagged wild type or the corresponding SLP65 mutant were cultured in light (Lys $+0 / \operatorname{Arg}+0$ ) or heavy (Lys $+8 / \operatorname{Arg}+10$ ) SILAC medium, respectively. SILAC-based mass spectrometric identification and relative quantification of all PXXXPR ligands were performed using biotinylated peptides encompassing the central proline/arginine motif of SLP65 as wild-type (KSPPPAAPSPLPR AGKKPT) or binding-inactive version (KSPPPAAPSALPAAGKKPT) for affinity purification experiments, with DT40 B cells that were metabolically labelled in heavy or light SILAC medium, respectively.

\section{Mass spectrometry analysis, database searching and MaxQuant-based protein quantification}

Proteins were separated by one-dimensional SDS-PAGE (4-12\% NuPAGE Bis-Tris Gel, Invitrogen) and the entire lane of the Coomassie blue-stained gel was cut into 23 slices. All slices were reduced with $10 \mathrm{mM}$ DTT for $55 \mathrm{~min}$ at $56^{\circ} \mathrm{C}$, alkylated with $55 \mathrm{mM}$ IAA for $20 \mathrm{~min}$ at $26^{\circ} \mathrm{C}$ and digested with modified trypsin (Promega) overnight at $37^{\circ} \mathrm{C}$. Tryptic peptides were injected into a C18 precolumn $(1.5 \mathrm{~cm}, 360 \mu \mathrm{m}$ o.d., $150 \mu \mathrm{m}$ i.d., Reprosil-Pur $120 \AA, 5 \mu \mathrm{m}, \mathrm{C} 18-\mathrm{AQ}$, Dr Maisch $\mathrm{GmbH}$ ) at a flow rate of $10 \mu \mathrm{l} / \mathrm{min}$. Bound peptides were eluted and separated on a C18 capillary column $(15 \mathrm{~cm}, 360 \mu \mathrm{m}$ o.d., $75 \mu \mathrm{m}$ i.d., Reprosil-Pur $120 \AA$, $5 \mu \mathrm{m}$, C18-AQ, Dr Maisch GmbH) at a flow rate of $300 \mathrm{nl} / \mathrm{min}$, with a gradient from 7.5 to $37.5 \%$ ACN in $0.1 \%$ formic acid for $60 \mathrm{~min}$ using an Agilent 1100 nano-flow LC system (Agilent Technologies) coupled to an LTQ-Orbitrap XL hybrid mass spectrometer (Thermo Electron). MS conditions were as followed: spray voltage, $1.8 \mathrm{kV}$; heated capillary temperature, $150^{\circ} \mathrm{C}$; normalized collision-induced dissociation (CID) collision energy $37.5 \%$ for MS/MS in LTQ. An activation $q=0.25$ and activation time of $30 \mathrm{~ms}$ were used. The mass spectrometer was operated in the data-dependent mode to automatically switch between MS and MS/MS acquisition. Survey MS spectra were acquired in the Orbitrap $(\mathrm{m} / z$ 350-1600) with the resolution set to 30000 at $\mathrm{m} / \mathrm{z} 400$ and automatic gain control target at $5 \times 10^{5}$. The five most intense ions were sequentially isolated for CID MS/MS fragmentation and detection in the linear ion trap. Ions with single and unrecognized charge states were excluded. Raw data were analysed with MaxQuant software (Version 1.0.12.31) in combination with Mascot search engine for peptide and protein identifications (Version 2.2.04, Matrix Science). IPI Chicken (Version 3.47) was used as Gallus gallus sequence database. MS/MS peak lists were 
filtered to contain at most six peaks per $100 \mathrm{Da}$ interval and searched against Mascot server. The MS mass tolerance was set to 7 p.p.m. and MS/MS mass tolerance was set to $0.8 \mathrm{Da}$. Up to three missed cleavages of trypsin were allowed. Oxidized methionine and cysteine carbamido-methylation were searched as variable modifications. The modifications corresponding to arginine and lysine labelled with heavy stable isotopes were handled as fixed modifications in the Mascot search, if applicable, after identification of SILAC pairs by MaxQuant. The false positive rate was set to $1 \%$ at the peptide level, the false discovery rate was set to $1 \%$ at the protein level and the minimum required peptide length was set to six amino acids.

\section{Confocal laser scanning and TIRF microscopy}

B cells suspended in Krebs Ringer solution composed of $10 \mathrm{mM}$ HEPES (pH 7.0), $140 \mathrm{mM} \mathrm{NaCl}, 4 \mathrm{mM} \mathrm{KCl}, 1 \mathrm{mM} \mathrm{MgCl}_{2}, 1 \mathrm{mM} \mathrm{CaCl}_{2}$ and $10 \mathrm{mM}$ glucose at a concentration of $10^{6}$ cells/ml were seeded onto Lab-Tek ${ }^{\mathrm{TM}}$ chambered coverglasses, incubated at $37^{\circ} \mathrm{C}$ for $20 \mathrm{~min}$ and stimulated with $2 \mu \mathrm{g} / \mathrm{ml}$ of prewarmed M4 antibodies or $10 \mu \mathrm{g} / \mathrm{ml}$ of anti-mouse IgM antibodies. Cells were examined on a Leica TCS SP2 confocal laser scanning microscope. Citrine was excited at $514 \mathrm{~nm}$ and emission was recorded at $530-580 \mathrm{~nm}$. TIRF microscopy was performed as described (Fleire et al, 2006; Depoil et al, 2008; Weber et al, 2008).

\section{Supplementary data}

Supplementary data are available at The EMBO Journal Online (http://www.embojournal.org).

\section{References}

Abudula A, Grabbe A, Brechmann M, Polaschegg C, Herrmann N, Goldbeck I, Dittmann K, Wienands J (2007) SLP-65 signal transduction requires Src homology 2 domain-mediated membrane anchoring and a kinase-independent adaptor function of Syk. J Biol Chem 282: 29059-29066

Buday L, Wunderlich L, Tamas P (2002) The Nck family of adapter proteins: regulators of actin cytoskeleton. Cell Signal 14: 723-731

Cen O, Gorska MM, Stafford SJ, Sur S, Alam R (2003) Identification of UNC119 as a novel activator of SRC-type tyrosine kinases. J Biol Chem 278: $8837-8845$

Chiu CW, Dalton M, Ishiai M, Kurosaki T, Chan AC (2002) BLNK: molecular scaffolding through 'cis'-mediated organization of signaling proteins. EMBO J 21: 6461-6472

Cox J, Matic I, Hilger M, Nagaraj N, Selbach M, Olsen JV, Mann M (2009) A practical guide to the MaxQuant computational platform for SILAC-based quantitative proteomics. Nat Protoc 4: 698-705

Depoil D, Fleire S, Treanor BL, Weber M, Harwood NE, Marchbank KL, Tybulewicz VL, Batista FD (2008) CD19 is essential for $\mathrm{B}$ cell activation by promoting $\mathrm{B}$ cell receptor-antigen microcluster formation in response to membrane-bound ligand. Nat Immunol 9: 63-72

Dikic I (2002) CIN85/CMS family of adaptor molecules. FEBS Lett 529: $110-115$

Dustin ML, Olszowy MW, Holdorf AD, Li J, Bromley S, Desai N, Widder P, Rosenberger F, van der Merwe PA, Allen PM, Shaw AS (1998) A novel adaptor protein orchestrates receptor patterning and cytoskeletal polarity in T-cell contacts. Cell 94: 667-677

Engelke M, Engels N, Dittmann K, Stork B, Wienands J (2007) $\mathrm{Ca}(2+)$ signaling in antigen receptor-activated B lymphocytes. Immunol Rev 218: 235-246

Engels N, Engelke M, Wienands J (2008) Conformational plasticity and navigation of signaling proteins in antigen-activated B lymphocytes. Adv Immunol 97: 251-281

Engels N, Konig LM, Heemann C, Lutz J, Tsubata T, Griep S, Schrader V, Wienands J (2009) Recruitment of the cytoplasmic adaptor Grb2 to surface IgG and IgE provides antigen receptorintrinsic costimulation to class-switched B cells. Nat Immunol 10: 1018-1025

Engels N, Wollscheid B, Wienands J (2001) Association of SLP-65/ BLNK with the B cell antigen receptor through a non-ITAM tyrosine of Ig-alpha. Eur J Immunol 31: 2126-2134

Fleire SJ, Goldman JP, Carrasco YR, Weber M, Bray D, Batista FD (2006) B cell ligand discrimination through a spreading and contraction response. Science 312: 738-741

\section{Acknowledgements}

We thank Niklas Engels for helpful discussions and critical comments on the manuscript. We are grateful to Johanna Lehne, Uwe Plessmann, and Monika Raabe for their excellent technical assistance in MS analyses. Our research received funding from the European Community's Seventh Framework Program FP7/20072013 under grant agreement no 201549 (EURO-PADnet HEALTH-F22008-201549) and the Deutsche Forschungsgemeinschaft through FOR 521 and SFB 860.

Author contributions: TO designed and performed interactome analyses and analysed the signalling function of SLP adaptors. VB investigated subcellular targeting of CD2AP/CIN85, generated corresponding DT40 mutant cells and analysed their BCR signalling capacities. KN contributed to the generation of DT40 mutants and together with $\mathrm{HH}$ contributed to interactome analyses. HB generated and analysed the SLP76* variant. KD generated and analysed retrovirally transduced primary B cells. ME contributed to microscopic analysis of SLP adaptors. TS and FB performed live cell imaging by TIRF microscopy. HU supervised proteomic elucidation of the SLP65 interactome and JW supervised the project and wrote the paper.

\section{Conflict of interest}

The authors declare that they have no conflict of interest.

Fu C, Turck CW, Kurosaki T, Chan AC (1998) BLNK: a central linker protein in B cell activation. Immunity 9: 93-103

Geahlen RL (2009) Syk and pTyr'd: signaling through the B cell antigen receptor. Biochim Biophys Acta 1793: 1115-1127

Goitsuka R, Fujimura Y, Mamada H, Umeda A, Morimura T, Uetsuka K, Doi K, Tsuji S, Kitamura D (1998) BASH, a novel signaling molecule preferentially expressed in B cells of the bursa of Fabricius. J Immunol 161: 5804-5808

Gorska MM, Stafford SJ, Cen O, Sur S, Alam R (2004) Unc119, a novel activator of Lck/Fyn, is essential for T cell activation. $J$ Exp Med 199: 369-379

Graham SA, Jegouzo SA, Yan S, Powlesland AS, Brady JP, Taylor ME, Drickamer K (2009) Prolectin, a glycan-binding receptor on dividing B cells in germinal centers. J Biol Chem 284: 18537-18544

Hashimoto A, Okada H, Jiang A, Kurosaki M, Greenberg S, Clark EA, Kurosaki T (1998) Involvement of guanosine triphosphatases and phospholipase C-gamma 2 in extracellular signal-regulated kinase, c-Jun NH2-terminal kinase, and p38 mitogen-activated protein kinase activation by the B cell antigen receptor. $J$ Exp Med 188: $1287-1295$

Hashimoto S, Iwamatsu A, Ishiai $\mathrm{M}$, Okawa $\mathrm{K}$, Yamadori $\mathrm{T}$, Matsushita M, Baba Y, Kishimoto T, Kurosaki T, Tsukada S (1999) Identification of the SH2 domain binding protein of Bruton's tyrosine kinase as BLNK-functional significance of Btk-SH2 domain in B-cell antigen receptor-coupled calcium signaling. Blood 94: 2357-2364

Havrylov S, Redowicz MJ, Buchman VL (2010) Emerging roles of Ruk/CIN85 in vesicle-mediated transport, adhesion, migration and malignancy. Traffic 11: 721-731

Hayashi K, Nittono R, Okamoto N, Tsuji S, Hara Y, Goitsuka R, Kitamura D (2000) The B cell-restricted adaptor BASH is required for normal development and antigen receptor-mediated activation of B cells. Proc Natl Acad Sci USA 97: 2755-2760

Hutchcroft JE, Harrison ML, Geahlen RL (1991) B lymphocyte activation is accompanied by phosphorylation of a $72-\mathrm{kDa}$ protein-tyrosine kinase. J Biol Chem 266: 14846-14849

Hutchcroft JE, Harrison ML, Geahlen RL (1992) Association of the 72-kDa protein-tyrosine kinase PTK72 with the B cell antigen receptor. J Biol Chem 267: 8613-8619

Hutchings NJ, Clarkson N, Chalkley R, Barclay AN, Brown MH (2003) Linking the T cell surface protein CD2 to the actin-capping protein CAPZ via CMS and CIN85. J Biol Chem 278: 22396-22403

Ishiai M, Kurosaki M, Inabe K, Chan AC, Sugamura K, Kurosaki T (2000) Involvement of LAT, Gads, and Grb2 in compartmentation of SLP-76 to the plasma membrane. J Exp Med 192: 847-856 
Ishiai M, Kurosaki M, Pappu R, Okawa K, Ronko I, Fu C, Shibata M, Iwamatsu A, Chan AC, Kurosaki T (1999) BLNK required for coupling Syk to PLC gamma 2 and Rac1-JNK in B cells. Immunity 10: $117-125$

Jiang A, Craxton A, Kurosaki T, Clark EA (1998) Different protein tyrosine kinases are required for $\mathrm{B}$ cell antigen receptor-mediated activation of extracellular signal-regulated kinase, c-Jun NH2terminal kinase 1 , and p38 mitogen-activated protein kinase. $J$ Exp Med 188: 1297-1306

Jumaa H, Wollscheid B, Mitterer M, Wienands J, Reth M, Nielsen PJ (1999) Abnormal development and function of B lymphocytes in mice deficient for the signaling adaptor protein SLP-65. Immunity 11: $547-554$

Kabak S, Skaggs BJ, Gold MR, Affolter M, West KL, Foster MS, Siemasko K, Chan AC, Aebersold R, Clark MR (2002) The direct recruitment of BLNK to immunoglobulin alpha couples the B-cell antigen receptor to distal signaling pathways. Mol Cell Biol 22: 2524-2535

Kitaura Y, Jang IK, Wang Y, Han YC, Inazu T, Cadera EJ, Schlissel M, Hardy RR, Gu H (2007) Control of the B cell-intrinsic tolerance programs by ubiquitin ligases $\mathrm{Cbl}$ and $\mathrm{Cbl-b}$. Immunity 26: $567-578$

Kohler F, Storch B, Kulathu Y, Herzog S, Kuppig S, Reth M, Jumaa H (2005) A leucine zipper in the $\mathrm{N}$ terminus confers membrane association to SLP-65. Nat Immunol 6: 204-210

Kometani K, Yamada T, Sasaki Y, Yokosuka T, Saito T, Rajewsky K, Ishiai M, Hikida M, Kurosaki T (2011) CIN85 drives B cell responses by linking BCR signals to the canonical NF- $\kappa B$ pathway. J Exp Med 208: 1447-1457

Kowanetz K, Szymkiewicz I, Haglund K, Kowanetz M, Husnjak K, Taylor JD, Soubeyran P, Engstrom U, Ladbury JE, Dikic I (2003) Identification of a novel proline-arginine motif involved in CIN85dependent clustering of $\mathrm{Cbl}$ and down-regulation of epidermal growth factor receptors. J Biol Chem 278: 39735-39746

Kulathu Y, Hobeika E, Turchinovich G, Reth M (2008) The kinase Syk as an adaptor controlling sustained calcium signalling and Bcell development. EMBO J 27: 1333-1344

Kurakin AV, Wu S, Bredesen DE (2003) Atypical recognition consensus of CIN85/SETA/Ruk SH3 domains revealed by targetassisted iterative screening. J Biol Chem 278: 34102-34109

Le Clainche C, Carlier MF (2008) Regulation of actin assembly associated with protrusion and adhesion in cell migration. Physiol Rev 88: 489-513

Minegishi Y, Rohrer J, Coustan-Smith E, Lederman HM, Pappu R, Campana D, Chan AC, Conley ME (1999) An essential role for BLNK in human B cell development. Science 286: 1954-1957

Monroe JG (2006) ITAM-mediated tonic signalling through pre-BCR and BCR complexes. Nat Rev Immunol 6: 283-294

Neumann K, Oellerich T, Urlaub H, Wienands J (2009) The B-lymphoid Grb2 interaction code. Immunol Rev 232: 135-149

Oellerich T, Gronborg M, Neumann K, Hsiao HH, Urlaub $\mathrm{H}$, Wienands J (2009) SLP-65 phosphorylation dynamics reveals a functional basis for signal integration by receptor-proximal adaptor proteins. Mol Cell Proteomics 8: 1738-1750

Ong SE, Blagoev B, Kratchmarova I, Kristensen DB, Steen H, Pandey A, Mann M (2002) Stable isotope labeling by amino acids in cell culture, SILAC, as a simple and accurate approach to expression proteomics. Mol Cell Proteomics 1: 376-386

Pappu R, Cheng AM, Li B, Gong Q, Chiu C, Griffin N, White M, Sleckman BP, Chan AC (1999) Requirement for B cell linker protein (BLNK) in B cell development. Science 286: 1949-1954

Patterson HC, Kraus M, Kim YM, Ploegh H, Rajewsky K (2006) The $B$ cell receptor promotes $B$ cell activation and proliferation through a non-ITAM tyrosine in the Igalpha cytoplasmic domain. Immunity 25: 55-65
Scharenberg AM, Humphries LA, Rawlings DJ (2007) Calcium signalling and cell-fate choice in B cells. Nat Rev Immunol 7: 778-789

Schulze-Luehrmann J, Ghosh S (2006) Antigen-receptor signaling to nuclear factor kappa B. Immunity 25: 701-715

Selbach M, Paul FE, Brandt S, Guye P, Daumke O, Backert S, Dehio C, Mann M (2009) Host cell interactome of tyrosinephosphorylated bacterial proteins. Cell Host Microbe 5: 397-403

Stork B, Engelke M, Frey J, Horejsi V, Hamm-Baarke A, Schraven B, Kurosaki T, Wienands J (2004) Grb2 and the non-T cell activation linker NTAL constitute a $\mathrm{Ca}(2+)$-regulating signal circuit in $\mathrm{B}$ lymphocytes. Immunity 21: 681-691

Stork B, Neumann K, Goldbeck I, Alers S, Kahne T, Naumann M, Engelke M, Wienands J (2007) Subcellular localization of Grb2 by the adaptor protein Dok-3 restricts the intensity of $\mathrm{Ca} 2+$ signaling in B cells. EMBO J 26: 1140-1149

Su YW, Zhang Y, Schweikert J, Koretzky GA, Reth M, Wienands J (1999) Interaction of SLP adaptors with the SH2 domain of Tec family kinases. Eur J Immunol 29: 3702-3711

Take H, Watanabe S, Takeda K, Yu ZX, Iwata N, Kajigaya S (2000) Cloning and characterization of a novel adaptor protein, CIN85, that interacts with c-Cbl. Biochem Biophys Res Commun 268: $321-328$

Treanor B, Depoil D, Gonzalez-Granja A, Barral P, Weber M, Dushek O, Bruckbauer A, Batista FD (2010) The membrane skeleton controls diffusion dynamics and signaling through the $\mathrm{B}$ cell receptor. Immunity 32: 187-199

Watanabe S, Take H, Takeda K, Yu ZX, Iwata N, Kajigaya S (2000) Characterization of the CIN85 adaptor protein and identification of components involved in CIN85 complexes. Biochem Biophys Res Commun 278: 167-174

Weber M, Treanor B, Depoil D, Shinohara H, Harwood NE, Hikida M, Kurosaki T, Batista FD (2008) Phospholipase C-gamma2 and Vav cooperate within signaling microclusters to propagate B cell spreading in response to membrane-bound antigen. $J$ Exp Med 205: $853-868$

Wienands J, Larbolette O, Reth M (1996) Evidence for a preformed transducer complex organized by the B cell antigen receptor. Proc Natl Acad Sci USA 93: 7865-7870

Wienands J, Schweikert J, Wollscheid B, Jumaa H, Nielsen PJ, Reth M (1998) SLP-65: a new signaling component in B lymphocytes which requires expression of the antigen receptor for phosphorylation. J Exp Med 188: 791-795

Wong J, Ishiai M, Kurosaki T, Chan AC (2000) Functional complementation of BLNK by SLP-76 and LAT linker proteins. J Biol Chem 275: 33116-33122

Xu S, Tan JE, Wong EP, Manickam A, Ponniah S, Lam KP (2000) B cell development and activation defects resulting in xid-like immunodeficiency in BLNK/SLP-65-deficient mice. Int Immunol 12: $397-404$

Zhang J, Zheng X, Yang X, Liao K (2009) CIN85 associates with endosomal membrane and binds phosphatidic acid. Cell Res 19: 733-746

Zioncheck TF, Harrison ML, Isaacson CC, Geahlen RL (1988) Generation of an active protein-tyrosine kinase from lymphocytes by proteolysis. J Biol Chem 263: 19195-19202

(c) The EMBO Journal is published by Nature Publishing Group on behalf of European Molecular Biology Organization. This work is licensed under a Creative Commons Attribution-NoncommercialShare Alike 3.0 Unported License. [http://creativecommons. org/licenses/by-nc-sa/3.0/] 